\title{
Parameters controlling early age hydration of cement pastes containing accelerators for sprayed concrete
}

\author{
Renan P. Salvador ${ }^{\mathrm{a}, \mathrm{b}, 1}$, Sergio H. P. Cavalaro ${ }^{\mathrm{a}, 1}$, Maria A. Cincotto ${ }^{\mathrm{c}}$, Antonio D. de \\ Figueiredo ${ }^{c}$ \\ ${ }^{a}$ Department of Construction Engineering, BarcelonaTech, Polytechnic University of \\ Catalonia, UPC, Jordi Girona 1-3, 08034, Barcelona, Spain. \\ ${ }^{\mathrm{b}}$ CAPES Foundation, Ministry of Education of Brazil, Brasília - DF, 70040-020, Brazil. \\ ${ }^{c}$ Department of Civil Construction Engineering, Polytechnic School of University of São \\ Paulo, Professor Almeida Prado, Trav 2, 83, 05424-970, São Paulo, Brazil.
}

\begin{abstract}
The objective of this work is to parametrize the early age hydration behavior of accelerated cement pastes based on the chemical properties of cement and accelerators. Eight cements, three alkali-free and one alkaline accelerators were evaluated. Isothermal calorimetry, in situ XRD and SEM imaging were performed to characterize kinetics and mechanisms of hydration and the microstructure development. The reactivity of all accelerators is directly proportional to their aluminum and sulfate concentrations and to the amount and solubility of the setting regulator contained in cement. Alite hydration is enhanced if a proper $\mathrm{C}_{3} \mathrm{~A} / \mathrm{SO}_{3}$ ratio (between 0.67 and 0.90 ) remains after accelerator addition and if limestone filler is employed, because undersulfated $\mathrm{C}_{3} \mathrm{~A}$ reactions are avoided. Combinations of compatible materials are recommended to enhance the performance of the matrix and to prevent an undesirable hydration behavior and its consequences in mechanical strength development.
\end{abstract}

Keywords: Cement Paste, Accelerator, Hydration, Kinetics, Sprayed Concrete.

\footnotetext{
${ }^{1}$ Corresponding authors. Tel.: +34 934054247, Fax: +34 934011036

E-mail addresses: renan.picolo@upc.edu (R Salvador); sergio.pialarissi@upc.edu (S Cavalaro).
} 


\section{Introduction}

Accelerators are commonly used in sprayed concrete applied for the stabilization of tunnel walls. These chemicals alter the kinetics and mechanisms of hydration of the cementitious material, whose effects are the reduction in setting times and the increase in the rate of mechanical strength development [1-3]. As a result, accelerators enable the build-up of concrete layers with proper thicknesses, providing an adequate support to the unstable ground and improving safety in the jobsite [4].

Several factors influence the chemical processes occurring in accelerated matrices, such as the mix design and the application method [1,5]. Galobardes [6] and Salvador et al [7] concluded that CEM II/A-L has a better compatibility with accelerators based on aluminum sulfate than CEM I due to the addition of limestone filler. Maltese et al $[8,9]$ showed that the solubility of calcium sulfate used as a setting regulator in cement influences accelerator reactivity and setting times were reduced when hemihydrate was only the sulfate source.

The chemical composition of accelerators also plays an important role in hydration kinetics and mechanical strength evolution. Lootens et al [10] and Juilland [11] demonstrated that phosphoric acid used in accelerators formulations strongly decreases the rate and extension of alite hydration. When compared to formulations containing formic acid, final setting is retarded and compressive strength at $12 \mathrm{~h}$ is reduced by $50 \%$ [1]. Ultimate strength gain and modulus of elasticity are also negatively affected and reductions around $20 \%$ at 28 days have been reported [6].

Salvador et al [12] and Xu and Stark [13] showed that accelerators based on sodium aluminate solutions rapidly deplete sulfate ions from the liquid phase. Consequently, undersulfated $\mathrm{C}_{3} \mathrm{~A}$ reactions occur, suppressing alite hydration. Compressive strengths in alkaline accelerated sprayed concrete at $12 \mathrm{~h}$ and 7 days are respectively 70 and $20 \%$ lower when compared to concrete produced with accelerators based on aluminum sulfate [1]. Ultimate strengths are optimized when the $\mathrm{Al}_{2} \mathrm{O}_{3} / \mathrm{SO}_{4}{ }^{2-}$ ratio in alkali-free accelerators ranges between 0.38 and 0.60 [1].

Despite the relevant conclusions from former researches [6-13], variations in cement and accelerator compositions were analyzed separately and discussion of results was majorly qualitative. Therefore, a study combining the main variables affecting hydration kinetics of accelerated matrices is still necessary to parametrize the chemical 
interaction between cements and accelerators. Such approach would assist engineers in preliminary design studies to properly select materials without the need of numerous and extensive field spray trials, which are a common practice nowadays. This evaluation would also be an important reference to accelerator manufacturers for the development of formulations with enhanced performance with cements from different sources. Consequently, the performance of sprayed concrete could be optimized and an unpredictable hydration behavior and its consequences could be avoided.

The objective of this work is to parametrize the early age hydration behavior of accelerated cement pastes, focusing their application in sprayed concrete technology. Since sprayed concrete requires an adequate mechanical strength development until 24 of hydration to guarantee its proper applicability, the progress of the construction work and for safety issues, the analysis conducted in this paper is restricted to ages until $24 \mathrm{~h}$. The evolution of hydration and mechanical strength at later ages is the subject of the following part of this research, from which a second paper will be written [14].

An experimental program was conducted with 8 model cements produced from 2 types of clinker, different amounts and types of setting regulator and additions of limestone filler. Three alkali-free accelerators and one alkaline accelerator were formulated specifically for this study. Isothermal calorimetry, in situ X-ray diffraction and SEM analysis were performed to characterize the kinetics and mechanisms of hydration of accelerated pastes. By doing so, a better comprehension of how the hydration process is influenced by the chemical composition of the starting materials is achieved. Results obtained may have a significant repercussion on how to select compatible cements and accelerators to provide a proper mechanical strength development.

\section{Experimental methodology}

The experimental program was performed at the Laboratory of Technology of Structures Luis Agulló at Universitat Politècnica de Catalunya (UPC) and at the Scientific and Technological Center from Universitat de Barcelona (CCIT-UB). In the following sections, materials, production process and tests performed are described. 


\subsection{Nomenclature}

The abbreviations for the materials used in this study are presented in Table 1 and the nomenclature of cements and pastes is described in Table 2.

Table 1 - Abbreviations for the materials used.

\begin{tabular}{|c|c|c|}
\hline Material & Type and description & Abbreviation \\
\hline \multirow{2}{*}{ Clinker } & Ordinary & OPC \\
\hline & Sulfate-resisting & SRC \\
\hline \multirow{2}{*}{$\begin{array}{l}\text { Setting } \\
\text { regulator }\end{array}$} & Gypsum & G \\
\hline & Calcium sulfate hemihydrate & $\mathrm{H}$ \\
\hline \multirow{2}{*}{ Addition } & Limestone filler & $\mathrm{F}$ \\
\hline & Silica sand & - \\
\hline \multirow{4}{*}{ Accelerator } & Alkali-free, with $\mathrm{Al}_{2} \mathrm{O}_{3} / \mathrm{SO}_{4}{ }^{2-}$ molar ratio equal to 0.33 & AF 0.33 \\
\hline & Alkali-free, with $\mathrm{Al}_{2} \mathrm{O}_{3} / \mathrm{SO}_{4}{ }^{2-}$ molar ratio equal to 0.60 & AF 0.60 \\
\hline & Alkali-free, with $\mathrm{Al}_{2} \mathrm{O}_{3} / \mathrm{SO}_{4}{ }^{2-}$ molar ratio equal to 0.74 & AF 0.74 \\
\hline & Alkaline & $\mathrm{AK}$ \\
\hline
\end{tabular}

Table 2 - Nomenclature adopted in this paper.

\begin{tabular}{ccc}
\hline Material & Nomenclature & Example \\
\hline Cement & $\begin{array}{c}\text { 'clinker type and content' 'setting } \\
\text { regulator type and content' 'addition' }\end{array}$ & $\begin{array}{c}\text { OPC 94_G 6_F, } \\
\text { SRC 96_G 4 }\end{array}$ \\
\hline $\begin{array}{c}\text { Paste without } \\
\text { accelerator }\end{array}$ & 'cement type'_REF & OPC 98_G 2_REF \\
\hline $\begin{array}{c}\text { Paste with } \\
\text { accelerator }\end{array}$ & 'cement type' 'accelerator type and \\
dosage' & $\begin{array}{c}\text { OPC 96_G 4_AF 0.33 5\%, } \\
\text { OPC 96_H 3.38_F_AK 3\% }\end{array}$ \\
\hline
\end{tabular}

\subsection{Materials}

\subsubsection{Cements}

A total of 8 different types of cement were produced by manually homogenizing clinker, setting regulator and additions in an agate mortar for $5 \mathrm{~min}^{2}$. Their compositions

\footnotetext{
${ }^{2}$ This mixing procedure was considered appropriate according to trial tests. Four different batches of the same cement (OPC 96_G 4) were produced by this mixing procedure and tested by isothermal calorimetry
} 
are shown in Table 3 and descriptions and characterization of materials are presented subsequently.

Table 3 - Compositions of cements, in mass percentages.

\begin{tabular}{|c|c|c|c|c|c|}
\hline Nomenclature & $\begin{array}{l}\text { Clinker type } \\
\text { and content }\end{array}$ & $\begin{array}{l}\text { Setting regulator } \\
\text { type and content }\end{array}$ & $\begin{array}{c}\text { Silica sand } \\
\text { content }\end{array}$ & $\begin{array}{c}\text { Limestone } \\
\text { filler content }\end{array}$ & $\begin{array}{c}\mathrm{C}_{3} \mathrm{~A} / \mathrm{SO}_{3} \\
\text { molar ratio }\end{array}$ \\
\hline OPC 98_G 2 & OPC, $98.0 \%$ & $\mathrm{G}, 2.0 \%$ & - & - & 0.866 \\
\hline OPC 96_G 4 & OPC, $96.0 \%$ & $\mathrm{G}, 4.0 \%$ & - & - & 0.586 \\
\hline OPC 94_G 6 & OPC, $94.0 \%$ & G, $6.0 \%$ & - & - & 0.443 \\
\hline OPC 96_H 3.38 & OPC, $96.0 \%$ & $\mathrm{H}, 3.38 \%$ & $0.62 \%$ & - & 0.586 \\
\hline OPC 96_G 4_F & OPC, $83.52 \%$ & $\mathrm{G}, 3.48 \%$ & - & $13.0 \%$ & 0.586 \\
\hline OPC 94_G 6_F & OPC, $81.78 \%$ & G, $5.22 \%$ & - & $13.0 \%$ & 0.443 \\
\hline OPC 96_H 3.38_F & OPC, $83.52 \%$ & $\mathrm{H}, 2.94 \%$ & $0.54 \%$ & $13.0 \%$ & 0.586 \\
\hline SRC 96_G 4 & SRC, $96.0 \%$ & G, $4.0 \%$ & - & - & 0.182 \\
\hline
\end{tabular}

$\underline{\text { Clinkers }}$

Ordinary and sulfate-resisting clinkers were selected due to their different $\mathrm{C}_{3} \mathrm{~A}$ content, which plays a significant role on the overall hydration kinetics and on the evolution of alite hydration [11,15]. Table 4 shows their mineralogical composition determined by XRD-Rietveld refinement and their chemical composition determined by XRF spectrometry. Besides, Table 5 summarizes their physical properties. Figure 1 shows that clinkers present an analogous particle size distribution, which is important to control hydration kinetics and the rate of strength gain [16].

Table 4 - Mineralogical and chemical compositions of the clinkers.

\begin{tabular}{ccc||ccc}
\hline \multicolumn{3}{c||}{ Mineralogical composition } & \multicolumn{3}{c}{ Chemical composition } \\
\hline Compound & OPC (\%) & SRC (\%) & Compound & OPC (\%) & SRC (\%) \\
\hline $\mathrm{C}_{3} \mathrm{~S}$ & 71.0 & 67.3 & LOI & 0.20 & 0.13 \\
\hline $\mathrm{C}_{2} \mathrm{~S}$ & 7.4 & 11.9 & $\mathrm{CaO}$ & 65.6 & 65.8 \\
\hline $\mathrm{C}_{3} \mathrm{~A}_{\mathrm{c}}$ & 2.4 & 0.9 & $\mathrm{SiO}_{2}$ & 21.1 & 21.6 \\
\hline
\end{tabular}

at $20^{\circ} \mathrm{C}$, using a w/c equal to 0.45 . The standard deviation in the maximum value of the main hydration peak was in the range $\pm 0.1 \mathrm{~mW} / \mathrm{g}$ cement. 


\begin{tabular}{ccc|ccc}
\hline $\mathrm{C}_{3} \mathrm{~A}_{0}$ & 3.2 & 0.7 & $\mathrm{Al}_{2} \mathrm{O}_{3}$ & 5.1 & 4.2 \\
\hline $\mathrm{C}_{4} \mathrm{AF}$ & 12.8 & 15.9 & $\mathrm{Fe}_{2} \mathrm{O}_{3}$ & 3.4 & 4.9 \\
\hline $\mathrm{CaO}$ & 0.2 & 0.5 & $\mathrm{SO}_{3}$ & 1.2 & 1.0 \\
\hline $\mathrm{Ca}(\mathrm{OH})_{2}$ & 0.3 & 0.3 & $\mathrm{MgO}$ & 1.8 & 1.3 \\
\hline $\mathrm{CaCO}_{3}$ & 1.1 & 1.0 & $\mathrm{~K}_{2} \mathrm{O}$ & 0.94 & 0.57 \\
\hline $\mathrm{MgO}$ & 0.5 & 0.4 & $\mathrm{Na}_{2} \mathrm{O}$ & 0.13 & 0.10 \\
\hline $\mathrm{K}_{2} \mathrm{SO}_{4}$ & 0.3 & 0.1 & $\mathrm{TiO}_{2}$ & 0.22 & 0.20 \\
\hline $\mathrm{Na}_{2} \mathrm{SO}_{4}$ & 0.8 & 1.0 & Minor phases & 0.31 & 0.20 \\
\hline $\mathrm{Total} \mathrm{sum}$ & 100.0 & 100.0 & Total sum & 100.0 & 100.0 \\
\hline
\end{tabular}

Table 5 - Physical properties of the clinkers.

\begin{tabular}{ccc}
\hline Property & OPC & SRC \\
\hline Specific surface BET $\left(\mathrm{m}^{2} / \mathrm{g}\right)$ & 1.52 & 1.10 \\
\hline $\mathrm{d}_{10}(\mu \mathrm{m})$ & 1.81 & 2.37 \\
\hline $\mathrm{d}_{50}(\mu \mathrm{m})$ & 11.2 & 13.1 \\
\hline $\mathrm{d}_{90}(\mu \mathrm{m})$ & 29.9 & 33.4 \\
\hline
\end{tabular}

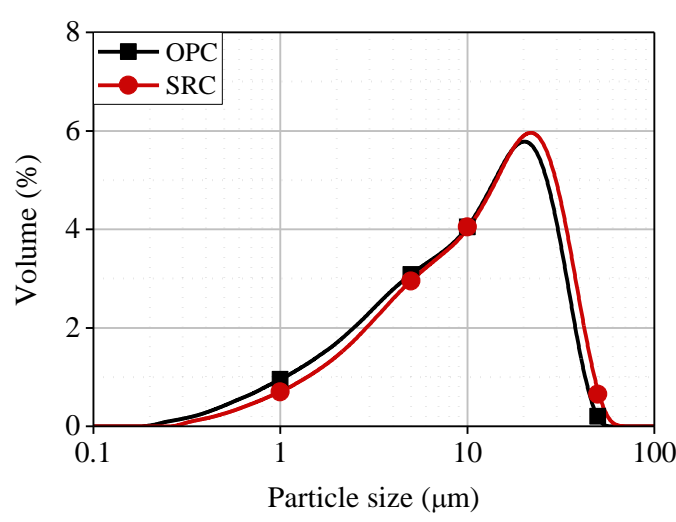

Figure 1 - Particle size distribution of the clinkers.

\section{Setting regulators}

Gypsum (99.5 \%, Sigma Aldrich) and calcium sulfate hemihydrate (99.5\%, Sigma Aldrich) were selected as setting regulators. These types of calcium sulfate are commonly found in cements. Gypsum is added to clinkers before grinding and may 
dehydrate partially, forming hemihydrate, due to the elevated temperature reached during this process [17]. As these compounds present different solubility $\left(\mathrm{CaSO}_{4} .2 \mathrm{H}_{2} \mathrm{O}: 0.255\right.$

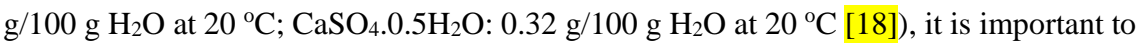
analyze how they affect the rate of accelerator reaction.

OPC cements were prepared with gypsum contents of 2.0, 4.0 and $6.0 \%$ to obtain total $\mathrm{SO}_{3}$ contents of $2.1,3.0$ and $4.0 \%$, respectively. Although the standard UNE EN 197-1:2011 [19] prescribes a minimum clinker content of $95.0 \%$ in a cement type I, cement OPC 94_G 6 (94.0\% of clinker and $6.0 \%$ of gypsum) was produced for exploratory tests. Only one cement was produced with the SRC clinker, using $4.0 \%$ of gypsum to maintain the same sulfate amount as in cement OPC 96_G 4.

Hemihydrate was added at $3.38 \%$ to produce OPC cements with the same molar amount of sulfate as $4.0 \%$ of gypsum. This difference is related to the lower water content in hemihydrate. Therefore, $0.62 \%$ of silica sand (calculated over the total mass of cement) was added with hemihydrate to maintain the same proportion of clinker and calcium sulfate.

\section{$\underline{\text { Additions }}$}

Limestone filler $\left(98 \% \mathrm{CaCO}_{3}, \mathrm{~d}_{50}=8.3 \mu \mathrm{m}\right)$ was used at the content of $13.0 \%$ in substitution of cement to reproduce CEM II/A-L used in former studies [6,7]. Silica sand $\left(98.5 \% \mathrm{SiO}_{2}, \mathrm{~d}_{50}=25.5 \mu \mathrm{m}\right)$ was added to counterbalance the lower water content in calcium sulfate hemihydrate, as mentioned in the former subsection.

\subsubsection{Water and superplasticizer}

For the preparation of cement pastes, deionized water (Mili-Q, $18 \mathrm{ohm} . \mathrm{s}$ ) was employed. The superplasticizer Sikaplast T1120, which is based on a polycarboxylate solution (34\% of solid content) and recommended for sprayed concrete applications, was also used. 


\subsubsection{Accelerators}

Four accelerators were formulated specifically for this experimental program and cover the categories commonly found in practice. Their composition and characteristics are summarized in Table 6.

Table 6 - Compositions and characteristics of accelerators.

\begin{tabular}{ccccc}
\hline Characteristic & AF 0.33 & AF 0.60 & AF 0.74 & AK \\
\hline $\mathrm{Al}_{2}\left(\mathrm{SO}_{4}\right)_{3}$ content $(\%)$ & 24.98 & 24.98 & 24.98 & - \\
\hline $\mathrm{Al}(\mathrm{OH})_{3}$ content $(\%)$ & - & 9.22 & 14.10 & 36.71 \\
\hline Formic acid content $(\%)$ & 11.48 & 11.48 & 11.48 & - \\
\hline $\mathrm{NaOH}$ content $(\%)$ & - & - & - & 12.26 \\
\hline Water content $(\%)$ & 63.54 & 54.32 & 49.44 & 57.00 \\
\hline $\mathrm{pH}$ at $20{ }^{\circ} \mathrm{C}$ & 2.8 & 3.0 & 2.9 & $12.0^{\mathrm{a}}$ \\
\hline $\mathrm{Al}_{2} \mathrm{O}_{3} / \mathrm{SO}_{4}{ }^{2-}$ molar ratio & 0.33 & 0.60 & 0.74 & - \\
\hline & a Solution at $1.0 \%$ & &
\end{tabular}

Alkali-free accelerators consist in aluminum sulfate solutions with additions of different amounts of aluminum hydroxide. Formic acid was used to keep the $\mathrm{pH}$ around 3.0 to avoid aluminum hydrolysis and the consequent precipitation of aluminum hydroxide. These formulations contain the same sulfate and formic acid contents, and the aluminum concentration was the only factor varying in their composition. Therefore, different $\mathrm{Al}_{2} \mathrm{O}_{3} / \mathrm{SO}_{4}{ }^{2-}$ molar ratios were obtained, varying from 0.33 (the same ratio as in ettringite) to 0.74 .

The alkaline accelerator is composed by an aqueous solution of aluminum and sodium hydroxides. $\mathrm{NaOH}$ is used to dissolve $\mathrm{Al}(\mathrm{OH})_{3}$, producing stable and soluble $\left[\mathrm{Al}(\mathrm{OH})_{4}\right]^{-}$ions. This accelerator does not contain sulfate ions.

As these formulations contain different aluminum/sulfate ratios, sulfate ions from cement may be consumed by accelerator reactions. Sulfate remaining after accelerator addition (corresponding to the sum of sulfate contents from cement and accelerator minus the sulfate content consumed by aluminum ions from accelerator to form ettringite) and the initial $\mathrm{C}_{3} \mathrm{~A}$ content of cements were used to calculate the final $\mathrm{C}_{3} \mathrm{~A} / \mathrm{SO}_{3}$ ratio of the paste, according to Final $\mathrm{C}_{3} \mathrm{~A} / \mathrm{SO}_{3}$ ratio $=$ 


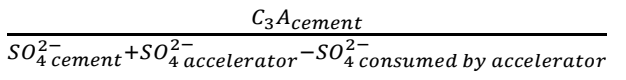

(Equation 1). This parameter is important to verify if cement pastes will behave as either properly or undersulfated, since high $\mathrm{C}_{3} \mathrm{~A} / \mathrm{SO}_{3}$ ratios may be detrimental for alite hydration [20], causing retardations in setting and strength evolution [21].

Final $\mathrm{C}_{3} \mathrm{~A} / \mathrm{SO}_{3}$ ratio $=\frac{\mathrm{C}_{3} \mathrm{~A}_{\text {cement }}}{\mathrm{SO}_{4}^{2-} \text { cement }}+\mathrm{SO}_{4 \text { accelerator }}^{-\mathrm{SO}_{4}^{2-} \text { consumed by accelerator }}$ (Equation 1$)$

\subsection{Composition and preparation of cement pastes}

Reference pastes (without accelerator) are composed by cement, a water/cement (w/c) ratio equal to 0.45 and $1.0 \%$ of superplasticizer by cement weight (\% bcw). In accelerated pastes, alkali-free accelerators were added in the dosages of 5.0 and $7.0 \%$ bcw, while the alkaline accelerator was used in the dosage of $3.0 \%$ bcw. Accelerators dosages were determined according to the procedure described by [1] to assure equivalent mechanical performance in pastes and fall within the dosages usually applied in tunnels executed with sprayed material. Water contents from superplasticizer and accelerators were deducted from the water added to the mix, in order to keep the final w/c ratio constant.

Reference pastes were prepared by pre-mixing water and superplasticizer and homogenizing the resulting solution with cement by means of a vortex external mixer during $60 \mathrm{~s}$. In accelerated pastes, accelerators were added $1 \mathrm{~h}$ after cement and water had been mixed. The resulting mixture was vigorously homogenized for $15 \mathrm{~s}$ with a spatula. During the period between the mixing of cement and water and accelerator addition, the paste was kept inside a calorimeter at $20^{\circ} \mathrm{C}$ in order to avoid the influence of variations in temperature.

This procedure intends to reproduce the condition usually found in practice, since accelerator addition occurs almost $1 \mathrm{~h}$ after the mixing of the other components. Moreover, this also allows a clearer evaluation of the heat flow attributed to accelerator reaction, which otherwise would overlap with the initial heat released in the mixing of cement and water. 


\subsection{Test methods}

Tests performed with accelerated pastes and the samples analyzed in each method are show in Table 7. Their descriptions are presented subsequently.

Table 7 - Tests performed with accelerated pastes and variables analyzed.

\begin{tabular}{ccc}
\hline Test & Number of tests & Samples analyzed \\
\hline $\begin{array}{c}\text { In situ XRD } \\
\begin{array}{c}\text { Isothermal } \\
\text { calorimetry }\end{array}\end{array}$ & 3 & OPC 96_G 4_AF 0.60 7\%, OPC 96_G 4_AF 0.74 7\% and \\
SRC 96_G 4_AF 0.74 7\%
\end{tabular}

In situ X-ray diffraction was performed with pastes OPC 96_G 4_AF 0.60 7\%, OPC 96_G 4_AF $0.747 \%$ and SRC 96_G 4_AF 0.74 7\%. These pastes were selected to evaluate how $\mathrm{Al}^{3+}$ concentration in accelerators and $\mathrm{C}_{3} \mathrm{~A}$ content in cements containing $4.0 \%$ of gypsum (resulting in different final $\mathrm{C}_{3} \mathrm{~A} / \mathrm{SO}_{3}$ ratios) influence the mechanisms and kinetics of hydration. Equipment and experimental conditions adopted for in situ XRD and structure models used for Rietveld refinement are described in [12]. Amorphous content was determined by the internal standard method (described in detail in [22]) to provide an indirect assessment of the C-S-H amount contained in the matrix. Alumina powder (SRM 676a, from NIST) was employed as an internal standard reference material. The temperature inside the diffractometer chamber was maintained at $26{ }^{\circ} \mathrm{C}$ (the sample holder used did not have a temperature control system). Therefore, all the preparation of the pastes for this test was performed at this temperature.

Isothermal calorimetry was performed at two different temperatures. The first series of tests comprised a total of 56 accelerated pastes, produced by the combination of 8 types of cement (Table 3), 3 alkali-free accelerators employed at 5.0 and $7.0 \%$ bcw and 1 alkaline accelerator used at $3.0 \%$ bcw (Table 6). The first series was performed at 20 ${ }^{\circ} \mathrm{C}$ during $24 \mathrm{~h}$ with $15.0 \mathrm{~g}$ of cement paste, using an I-cal 4000 isothermal calorimeter. Each paste was analyzed once, since the standard deviation in determining the heat of hydration of cement is below $2.0 \%$ [23].

The second series of tests comprised the 3 samples analyzed by in situ XRD (OPC 96_G 4_AF 0.60 7\%,OPC 96_G 4_AF 0.74 7\% and SRC 96_G 4_AF 0.74 7\%). As the temperature during the XRD measurements was maintained at $26{ }^{\circ} \mathrm{C}$, isothermal 
calorimetry was also performed at $26{ }^{\circ} \mathrm{C}$ with these pastes, in order to compare the phase evolution during hydration with the heat flow curves. All the preparation of the pastes for this test was conducted at this temperature (samples were kept at $26^{\circ} \mathrm{C}$ before accelerator addition). In this case, tests were performed during $48 \mathrm{~h}$, in the same calorimeter employed for the first series of tests. The temperature of all the materials was stabilized at either 20 or $26^{\circ} \mathrm{C}$ for $3 \mathrm{~h}$ before the beginning of each test.

Scanning electron microscopy was performed with pastes OPC 96_G 4_F_AF $0.607 \%$ and OPC 96_G 4_F_AK 3\% with the aim to analyze how the presence of limestone filler influences the microstructure after accelerator reaction. This analysis was conducted in a JEOL JSM 7100F microscope at the voltage of $20 \mathrm{kV}$. Cement pastes were frozen in liquid nitrogen $15 \mathrm{~min}$ after accelerator homogenization, dried in vacuum during $24 \mathrm{~h}$ and coated with carbon. Morphology of the precipitated hydrates was analyzed by secondary electron imaging of fracture surfaces and their chemical composition was assessed by energy dispersive X-ray analysis.

\section{Results and discussion}

3.1. Evolution of phase composition during hydration and its relation to the heat flow curves

The quantitative evolution of phase composition and the associated heat flow curves obtained at $26{ }^{\circ} \mathrm{C}$ are presented altogether in Figure 2. In order to simplify the interpretation of the graphs, only the reacting phases (alite, $\mathrm{C}_{3} \mathrm{~A}$, gypsum, portlandite, ettringite and $\mathrm{AFm}$ ) are presented. Slow reacting phases (belite and ferrite) were not plotted. C-S-H has a low degree of crystallinity and can only be quantified indirectly by the content of amorphous phases. 


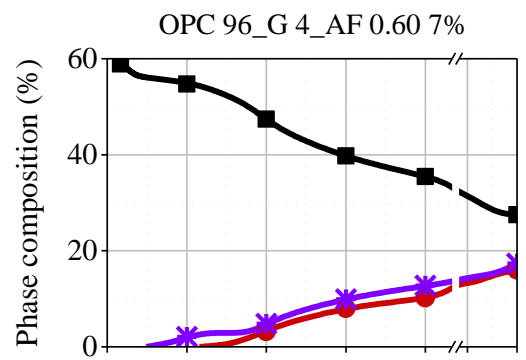

(a)

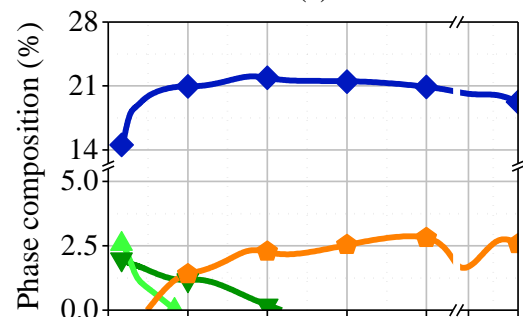

(d)

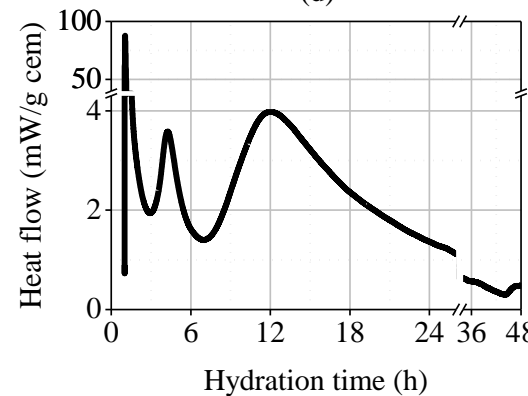

(g)
OPC 96_G 4_AF $0.747 \%$

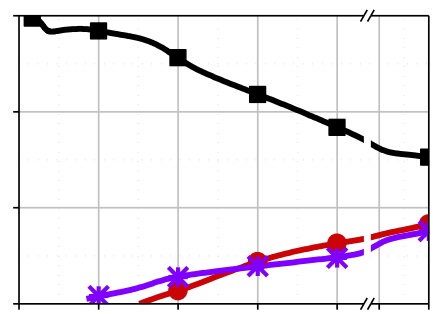

(b)

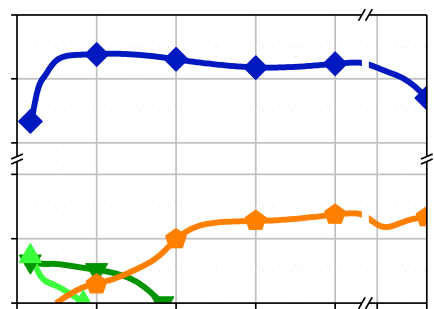

(e)

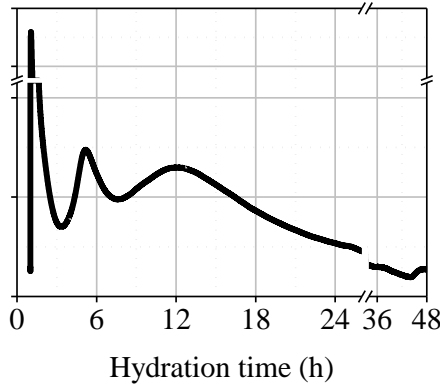

(h)
SRC 96_G 4_AF $0.747 \%$

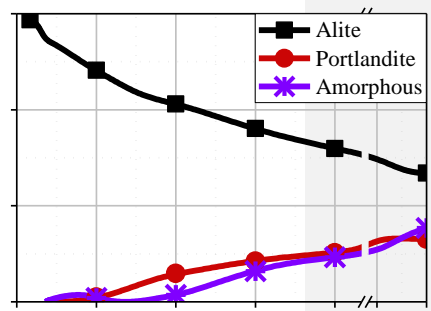

(c)

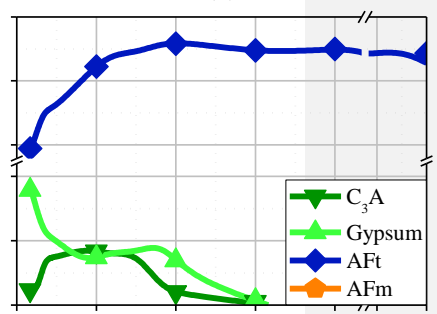

(f)

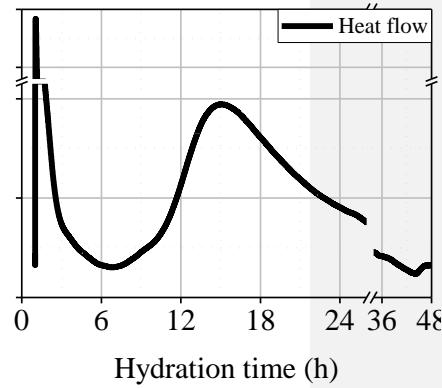

(i)

Figure 2 - Evolution of alite, portlandite and amorphous contents (a, b, c), $\mathrm{C}_{3} \mathrm{~A}$, gypsum, ettringite and AFm phases (d, e, f) and heat flow curves (g, h, i) obtained with pastes OPC 96_G 4_AF $0.607 \%$ (left), OPC 96_G 4_AF $0.747 \%$ (medium) and SRC 96_G 4_AF $0.747 \%$ (right) at $26{ }^{\circ} \mathrm{C}$.

All the pastes present a massive precipitation of ettringite due to accelerator reaction. ( $\left[\mathrm{Al}(\mathrm{OH})_{4}\right]^{-}$ions from accelerator consume $\mathrm{Ca}^{2+}$ and $\mathrm{SO}_{4}{ }^{2-}$ ions from the liquid phase, forming ettringite, according to Chemical equation 1 [17]). This process is associated with the sharp exothermic signal in the heat flow curve at $1 \mathrm{~h}$ (named accelerator peak hereinafter). Initial $\mathrm{C}_{3} \mathrm{~A}$ hydration with gypsum also produces ettringite, but at a minor extent. The amount of ettringite precipitated initially is directly proportional to $\mathrm{Al}^{3+}$ concentration in accelerators and to $\mathrm{C}_{3} \mathrm{~A}$ content in cement (OPC 96 G 4_AF 0.74 7\% > OPC 96 G 4_AF 0.60 7\% > SRC 96 G 4_AF 0.74 7\%). The amount 
of gypsum left after accelerator addition follows the reverse order of the quantity of ettringite formed, as expected.

$$
2\left[\mathrm{Al}(\mathrm{OH})_{4}\right]^{-}+6 \mathrm{Ca}^{2+}+4 \mathrm{OH}^{-}+3 \mathrm{SO}_{4}^{2-}+26 \mathrm{H}_{2} \mathrm{O} \rightleftharpoons \mathrm{C}_{3} \mathrm{~A} .3 \mathrm{CaSO}_{4} \cdot 32 \mathrm{H}_{2} \mathrm{O}
$$

In paste OPC 96_G 4_AF 0.60 7\%, gypsum remaining after accelerator reaction ( $2.6 \%$ by mass) dissolves to balance $\mathrm{Ca}^{2+}$ and $\mathrm{SO}_{4}{ }^{2-}$ concentrations in the liquid phase. In addition, it is constantly consumed by $\mathrm{C}_{3} \mathrm{~A}$, with consequent ettringite formation until $3 \mathrm{~h}$. At this time, gypsum depletes and $\mathrm{C}_{3} \mathrm{~A}$ starts to react with ettringite, forming monosulfoaluminate. This process corresponds to the exothermic peak between 3 and 7 $\mathrm{h}$ in the heat flow curve. This paste is undersulfated because $\mathrm{C}_{3} \mathrm{~A}$ hydrates before the onset of silicate hydration $[15,20]$.

Alite is consumed slowly until $7 \mathrm{~h}$, increasing calcium and silicate ions concentrations in the chemical equilibria. At $7 \mathrm{~h}$, the onset of the main hydration peak occurs, increasing the rate of alite consumption and portlandite and amorphous phases precipitation. $\mathrm{C}_{3} \mathrm{~A}$ continues reacting with ettringite, forming $\mathrm{AFm}$ phases, during the acceleration period until $13 \mathrm{~h}$. Finally, the deceleration period starts and hydration proceeds at a slow rate from $24 \mathrm{~h}$ on. $53.3 \%$ of alite were consumed until $48 \mathrm{~h}$ of hydration.

Paste OPC 96_G 4_AF 0.74 7\% presents the same hydration behavior as OPC 96_G 4_AF $0.607 \%$. However, as accelerator AF 0.74 contains $23 \%$ more $\mathrm{Al}^{3+}$ than AF 0.60 (Table 6), less gypsum remains after accelerator reaction (1.8\% by mass). In addition, faster rates of ettringite precipitation and gypsum consumption are observed. The maximum ettringite content is achieved at $3 \mathrm{~h}$, coinciding with gypsum depletion, the onset of the accelerated $\mathrm{C}_{3} \mathrm{~A}$ hydration and the beginning of $\mathrm{AFm}$ phases formation. Due to lower gypsum amounts, the peak related to $\mathrm{C}_{3} \mathrm{~A}$ hydration is wider and less intense than in paste OPC 96_G 4_AF 0.60 7\% (similarly to results from [24]).

The larger amount of aluminate hydrated phases precipitated until $3 \mathrm{~h}$ when accelerator AF 0.74 is employed contributes to a larger space filling in the matrix. In addition, aluminum in solution may be adsorbed con C-S-H nuclei or even substitute silicon in calcium silicate hydrate, forming C-A-S-H [25]. This phase does not act as a nucleation site and, therefore, induction periods are increased. Furthermore, the 
incorporation of aluminum on the surface of silicate-containing phases decreases their solubility and reactivity, as indicated by [26].

The combination of these processes is detrimental for alite hydration and for mechanical strength development. In paste OPC 96_G 4_AF 0.74 7\%, alite dissolution is inhibited, the onset of the main hydration peak is retarded (it starts around $7.8 \mathrm{~h}$ ) and reaction rates during the acceleration peak are slower. In this paste, $48.7 \%$ of alite hydrated until $48 \mathrm{~h}$ (9.4\% less than in paste OPC 96_G 4_AF 0.60 7\%).

The hydration behavior of paste SRC 96_G 4_AF 0.74 7\% differs from the other pastes analyzed. Initial ettringite amount in this paste is the lowest because the SRC clinker contains 3 times less $\mathrm{C}_{3} \mathrm{~A}$ than the OPC clinker (Table 4). As a result, the amount of gypsum left after accelerator addition is the highest ( $4.5 \%$ by mass). Furthermore, as this paste presents the lowest final $\mathrm{C}_{3} \mathrm{~A} / \mathrm{SO}_{3}$ ratio $(0.41)$, the rate of $\mathrm{C}_{3} \mathrm{~A}$ hydration is slower and gypsum depletes after the acceleration period of alite hydration. The maximum ettringite content is achieved around $12 \mathrm{~h}$ of hydration and is maintained constant after that. AFm phases were not detected until the end of this test.

Paste SRC 96_G 4_AF $0.747 \%$ is properly sulfated, because $\mathrm{C}_{3} \mathrm{~A}$ hydration occurs after the onset of the main hydration peak $[15,20]$. Since the early space filling caused by accelerated undersulfated $\mathrm{C}_{3} \mathrm{~A}$ reactions is avoided, alite hydration is not negatively affected. In fact, alite is constantly consumed during the induction period to balance the chemical equilibria disturbed by the accelerator. The rate of reaction during the acceleration period is 3.8 times higher than in OPC 96_G 4_AF 0.74 7\%. Until $48 \mathrm{~h}$, $54.5 \%$ of alite were consumed ( $12 \%$ more than in the equivalent OPC paste).

The observations derived from in situ XRD suggest a competition between silicate and aluminate hydrations. $\mathrm{C}_{3} \mathrm{~A}$ hydration is significantly affected by the addition of accelerators, especially by the ones containing higher $\mathrm{Al}^{3+}$ concentrations. The large amount of aluminate hydrates formed by accelerator reaction and accelerated undersulfated $\mathrm{C}_{3} \mathrm{~A}$ reactions inhibit alite hydration, lowering its extent and intensity.

Based on the results obtained in this section and on previous researches regarding accelerated hydration $[7,12,13,27]$, the chemical processes occurring during hydration were associated with the heat flow curves. Figure 3 identifies 5 general hydration stages, which are described in Table 8 (different chemical processes may occur depending on the composition of cements and accelerators). Their description will be used to interpret further analyses by isothermal calorimetry (stage I was not considered in the analyses). 


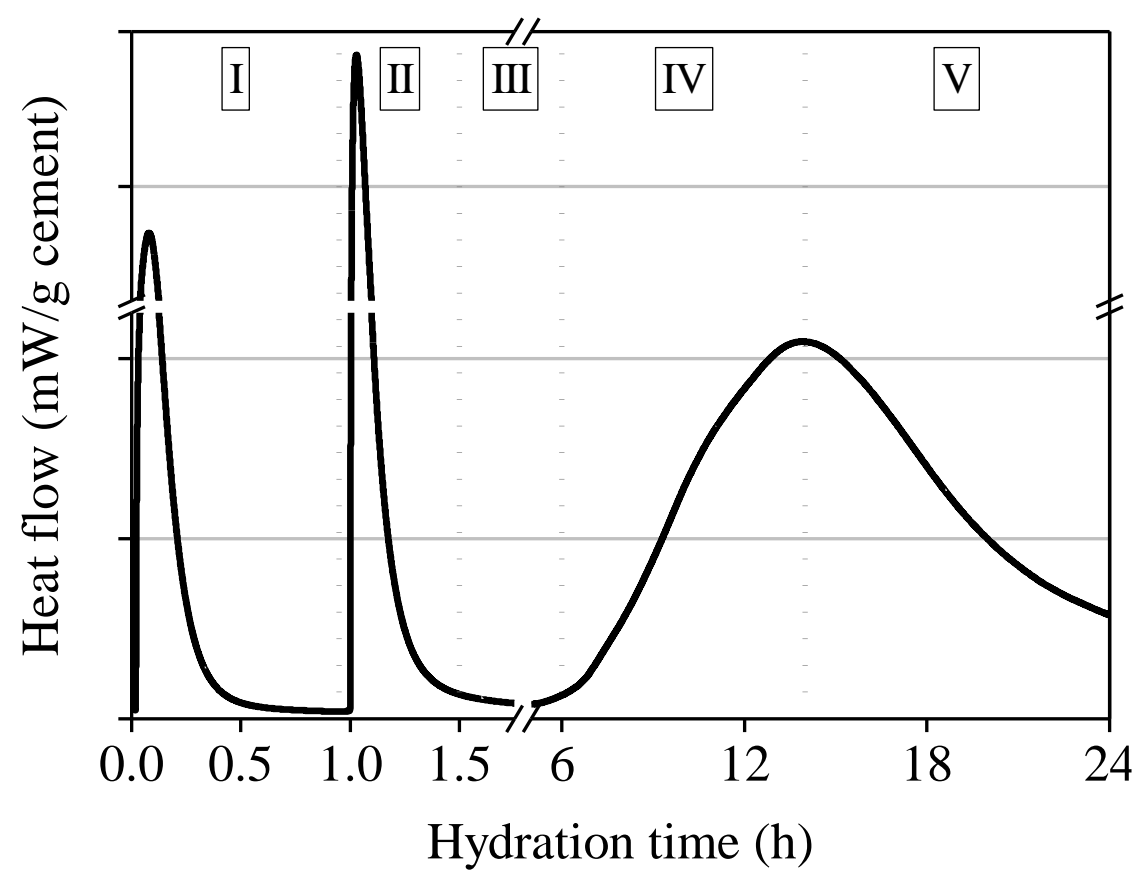

Figure 3 - Designation of 5 stages during hydration of an accelerated cement paste (Y-axis does not correspond to a real scale).

Table 8 - Chemical and physical processes occurring in each stage during hydration of an accelerated cement paste.

\begin{tabular}{|c|c|c|c|}
\hline Period & Designation & Chemical processes & Physical processes \\
\hline I & $\begin{array}{l}\text { Pre-induction } \\
\text { period }\end{array}$ & $\begin{array}{l}\text { Rapid dissolution of alkali sulfates, gypsum, } \\
\text { alite and aluminate phases. Initial formation } \\
\text { of ettringite. }\end{array}$ & $\begin{array}{c}\text { Large heat release. Formation of } \\
\text { aluminate hydrates influence rheology } \\
\text { of the paste. }\end{array}$ \\
\hline II & $\begin{array}{l}\text { Accelerator } \\
\text { reaction (named } \\
\text { accelerator peak } \\
\text { in the text) }\end{array}$ & $\begin{array}{l}\text { Massive precipitation of ettringite. } \\
\left.\text { [Al }(\mathrm{OH})_{4}\right]^{-} \text {from accelerator consumes } \mathrm{Ca}^{2+} \\
\text { and } \mathrm{SO}_{4}{ }^{2-} \text { from the liquid phase to form } \\
\text { ettringite (Chemical equation } 1) \text {. Alite may } \\
\text { be partially dissolved if accelerator is acidic. }\end{array}$ & $\begin{array}{l}\text { Large heat release. Ettringite } \\
\text { formation increases the solid/liquid } \\
\text { ratio of the matrix, the paste stiffens, } \\
\text { increasing early strength. Depending } \\
\text { on accelerator reactivity, initial and } \\
\text { final setting may occur. }\end{array}$ \\
\hline III & $\begin{array}{l}\text { Induction } \\
\text { period }\end{array}$ & $\begin{array}{l}\text { Low activity during this stage. Alite and } \\
\text { gypsum dissolve to balance } \mathrm{Ca}^{2+} \text { and } \mathrm{SO}_{4}{ }^{2-} \\
\text { concentrations in the chemical equilibria, } \\
\text { previously disturbed by accelerators. } \\
\text { Gypsum may deplete, depending on the } \\
\text { amount of sulfate consumed by accelerator, } \\
\text { and undersulfated } \mathrm{C}_{3} \mathrm{~A} \text { reactions may occur. }\end{array}$ & $\begin{array}{l}\text { Low heat evolution. Continuous } \\
\text { formation of ettringite increases the } \\
\text { viscosity of the paste. If undersulfated } \\
\mathrm{C}_{3} \mathrm{~A} \text { reactions occurs, a large heat } \\
\text { release is observed during the } \\
\text { induction period. }\end{array}$ \\
\hline IV & $\begin{array}{l}\text { Acceleration } \\
\text { period }\end{array}$ & $\begin{array}{l}\text { The rate of alite hydration increases, with } \\
\text { consequent formation of portlandite and C- } \\
\text { S-H. } \mathrm{C}_{3} \mathrm{~A} \text { hydration continues (forming } \\
\text { either ettringite, if sulfates are present, or } \\
\text { monosulfoaluminate, in the absence of } \\
\text { dissolved sulfates). }\end{array}$ & $\begin{array}{l}\text { High rate of heat release. The matrix } \\
\text { hardens, mechanical strength } \\
\text { increases and porosity decreases. }\end{array}$ \\
\hline
\end{tabular}




\begin{tabular}{|c|c|c|c|}
\hline V & $\begin{array}{l}\text { Deceleration } \\
\text { period }\end{array}$ & $\begin{array}{c}\text { The rate of alite hydration decreases. } \mathrm{C}_{3} \mathrm{~A} \\
\text { hydration consumes ettringite, forming } \\
\text { monosulfoaluminate. }\end{array}$ & $\begin{array}{l}\text { Mechanical strength increases at low } \\
\text { rates, porosity decreases and } \\
\text { shrinkage may occur. }\end{array}$ \\
\hline
\end{tabular}

\subsection{Influence of cement and accelerator compositions on the kinetics and}

\section{mechanisms of hydration of accelerated pastes}

Results obtained by isothermal calorimetry performed at $20{ }^{\circ} \mathrm{C}$ with all the pastes analyzed are presented from Figure A.1 to Figure A.8, in the appendix. To analyze the influence of different mix compositions on hydration, the parameters described in Table 9 were used to analyze heat of hydration curves. Results obtained by their calculation are shown in Table A.1, also located in the appendix. The conclusions derived from each parameter analyzed are presented from sections 3.2.1 to 3.2.7.

Table 9 - Parameters and methods for their calculation employed to analyze the hydration behavior of different mix compositions.

\begin{tabular}{|c|c|c|}
\hline Process & Parameter & Method for calculation \\
\hline \multirow{2}{*}{$\begin{array}{l}\text { Accelerator } \\
\text { reactivity }\end{array}$} & Accelerator reaction rate & Slope of the ascending part of the accelerator peak \\
\hline & Energy released by accelerator reaction & Area under the accelerator peak from 1 to $1.5 \mathrm{~h}$ \\
\hline \multirow{4}{*}{$\begin{array}{c}\text { Cement } \\
\text { hydration }\end{array}$} & Length of induction period & $\begin{array}{c}\text { Period between } 1.5 \mathrm{~h} \text { (end of the accelerator peak) } \\
\text { and the onset of the main hydration peak }\end{array}$ \\
\hline & Cement hydration rate & Slope of the ascending part of the acceleration period \\
\hline & $\begin{array}{l}\text { Energy released during the main } \\
\text { hydration peak }\end{array}$ & $\begin{array}{l}\text { Area under the curve between the end of the } \\
\text { induction period and the time when the heat flow } \\
\text { reaches } 1.0 \mathrm{~mW} / \mathrm{g} \text { cement in the deceleration period }\end{array}$ \\
\hline & Degree of hydration until $24 \mathrm{~h}$ & $\begin{array}{l}\text { Total energy released until } 24 \mathrm{~h} \text { minus the energy } \\
\text { released by accelerator reaction }\end{array}$ \\
\hline
\end{tabular}

\subsection{1. $\mathrm{Al}^{3+}$ content in accelerator and accelerator dosage}

As the quantity of $\mathrm{Al}^{3+}$ introduced in the paste depends on accelerator dosage, these parameters are analyzed simultaneously. Considering ettringite as the only sulfoaluminate hydrate immediately formed by accelerator reaction [12], the theoretical ettringite amounts produced by each accelerator are presented in Table 10. The higher the $\mathrm{Al}^{3+}$ content incorporated in the paste, the larger the amount of ettringite produced.

Table 10 - Theoretical amounts of ettringite formed by accelerator reaction. 


\begin{tabular}{cccc}
\hline Accelerator & $\begin{array}{c}\text { Dosage } \\
(\% \mathbf{~ b c w )})\end{array}$ & $\begin{array}{c}\mathbf{A l}^{3+} \text { introduced in the } \\
\text { paste (mmol/g cement) }\end{array}$ & $\begin{array}{c}\text { Ettringite formed } \\
(\mathbf{m m o l} / \mathbf{g} \text { cement) }\end{array}$ \\
\hline \multirow{2}{*}{$\mathrm{AF} 0.33$} & 5.0 & 0.0730 & 0.0365 \\
\cline { 2 - 4 } & 7.0 & 0.102 & 0.0510 \\
\hline \multirow{2}{*}{$\mathrm{AF} \mathrm{0.60}$} & 5.0 & 0.132 & 0.0660 \\
\cline { 2 - 4 } & 7.0 & 0.185 & 0.0925 \\
\hline \multirow{2}{*}{$\mathrm{AF} 0.74$} & 5.0 & 0.163 & 0.0815 \\
\cline { 2 - 4 } & 7.0 & 0.228 & 0.114 \\
\hline \multirow{2}{*}{$\mathrm{AK}$} & 3.0 & $0.141^{\mathrm{a}}$ & 0.0706 \\
\hline
\end{tabular}

${ }^{a} \mathrm{As}\left[\mathrm{Al}(\mathrm{OH})_{4}\right]$.

Figure 4 shows the influence of $\mathrm{Al}^{3+}$ content on the accelerator peak in pastes OPC 98_G 2, OPC 96_G 4 and OPC 94_G 6. The energy released follows the ascending order of the amount of ettringite precipitated, according to each accelerator and dosage (Table 8). However, accelerator reaction rate presents a saturation point at $0.185 \mathrm{mmol}$ of $\mathrm{Al}^{3+}$ / $\mathrm{g}$ cement in all cements analyzed. Accelerator efficiency decreases above this limit probably due to a lack of sulfates dissolved in the medium. The rate of gypsum dissolution is lower than the rate of accelerator reaction and AFm phases may be formed at the moment of accelerator addition [12]. 


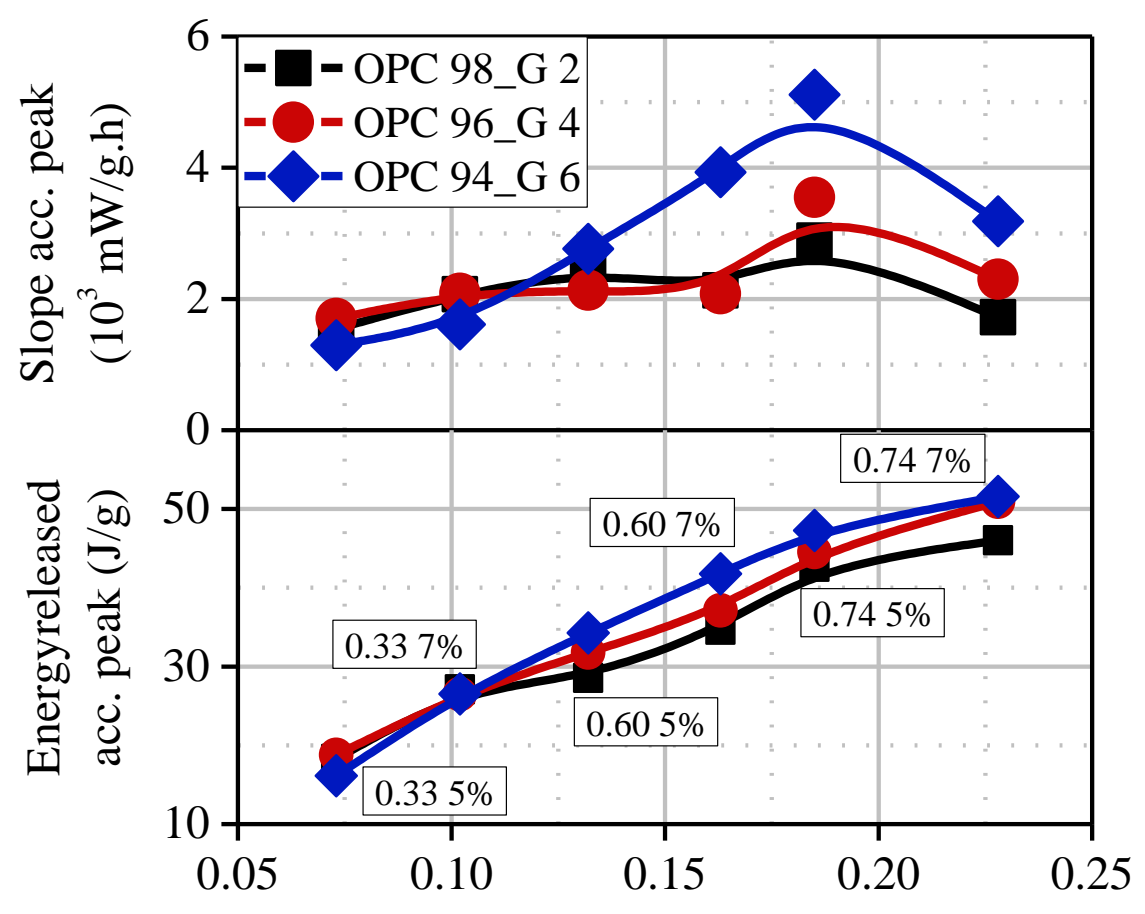

$\mathrm{Al}^{3+}$ in accelerator (mmol/g cement)

Figure 4 - Influence of $\mathrm{Al}^{3+}$ content introduced in the paste on the accelerator peak.

\subsection{2. $\mathrm{Al}_{2} \mathrm{O}_{3} / \mathrm{SO}_{4}{ }^{2-}$ molar ratio in accelerator}

The influence of the $\mathrm{Al}_{2} \mathrm{O}_{3} / \mathrm{SO}_{4}{ }^{2-}$ ratio in accelerators on the overall hydration behavior is presented in Figure 5. Since AF 0.33 provides the lowest amount of sulfoaluminate hydrates at the moment of its addition, early space filling is not prejudicial for alite hydration to proceed normally. The shape of the main hydration peak (Figure A.1, Figure A.2, Figure A.3) indicates that cement hydration mechanisms are not negatively affected by this admixture. Since no sulfates from cement are required for accelerator reaction, $\mathrm{C}_{3} \mathrm{~A}$ hydrates in a properly sulfated medium and $\mathrm{AFm}$ phases are formed after the acceleration period of silicate hydration. Due to these reasons, the energy released during the main hydration peak in all the pastes containing AF 0.33 is the highest when compared to equivalent pastes with the other alkali-free accelerators at the same dosage. 


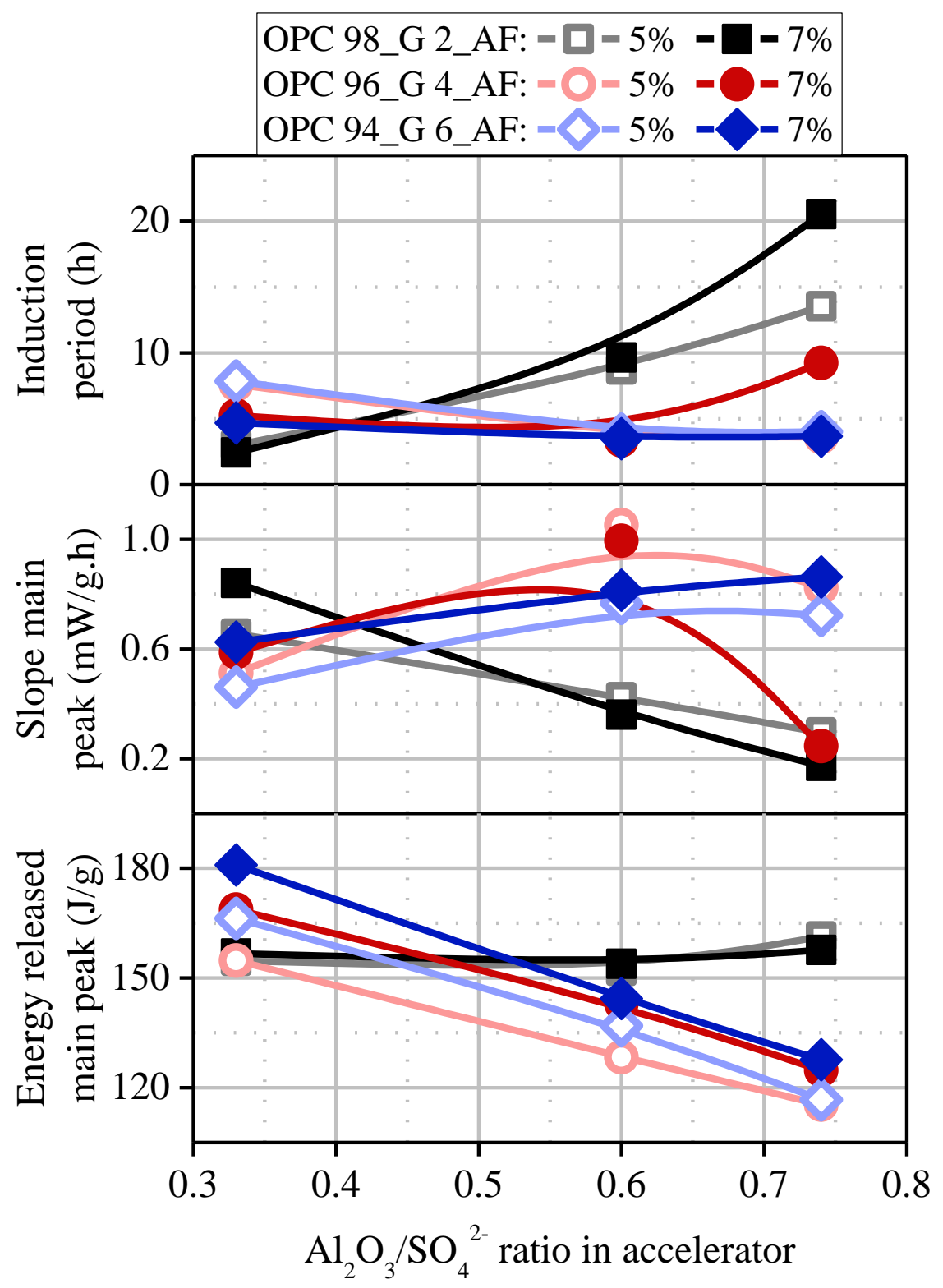

Figure 5 - Influence of $\mathrm{Al}_{2} \mathrm{O}_{3} / \mathrm{SO}_{4}{ }^{2-}$ ratio on the main hydration peak.

Accelerator AF 0.60 promotes shorter induction periods, faster hydration rates and higher intensities in the main hydration peak than AF 0.33 in all the pastes. Since AF 0.60 
contains $81 \%$ more $\mathrm{Al}^{3+}$ than $\mathrm{AF} 0.33$, the imbalance in the chemical equilibria caused by accelerator reaction favors gypsum and alite dissolutions. In addition, $\mathrm{C}_{3} \mathrm{~A}$ reactions are accelerated and the resulting hydration rate in the main peak corresponds to the sum of silicate and aluminate hydrations.

The tendencies observed for AF 0.74 depend on accelerator dosage and gypsum amount in cement. In pastes OPC 98_G 2_AF 0.745 and 7\% and OPC 96_G 4_AF 0.74 $7 \%$, induction periods are significantly increased and the reaction rate during the main hydration peak are reduced. As this accelerator contains the highest $\mathrm{Al}^{3+}$ concentration and $\mathrm{Al}_{2} \mathrm{O}_{3} / \mathrm{SO}_{4}{ }^{2-}$ ratio, the large amount of sulfoaluminate hydrates formed fills up the space available in the paste. The elevated consumption of sulfate ions from the liquid phase promotes undersulfated $\mathrm{C}_{3} \mathrm{~A}$ reactions, with the consequent formation of $\mathrm{AFm}$ phases before the onset of the main hydration peak. The result of these processes is a great suppress in alite dissolution and further hydration. Pastes OPC 94_G 6 are not negatively affected by $\mathrm{AF} 0.74$, because the high $\mathrm{Al}_{2} \mathrm{O}_{3} / \mathrm{SO}_{4}{ }^{2-}$ ratio in accelerator is counterbalanced by the larger gypsum content in cement.

\subsubsection{Gypsum amount in cement and final $\mathrm{C}_{3} \mathrm{~A} / \mathrm{SO}_{3}$ ratio of the paste}

The influence of gypsum amount on the accelerator peak in pastes containing alkali-free accelerators can also be analyzed in Figure 4. Reaction rate and the energy released in the accelerator peak are proportional to gypsum amount in cement, mainly for AF 0.60 and AF 0.74 in both dosages. An addition of $2.0 \%$ of gypsum increases the energy released by $10 \%$ and reaction rate by a minimum of $30 \%$. AF 0.33 does not follow this tendency because it does not require sulfates from the liquid phase.

Cement hydration kinetics after accelerator reaction is very sensitive to gypsum amount and the final $\mathrm{C}_{3} \mathrm{~A} / \mathrm{SO}_{3}$ ratio in the paste. Figure 6 presents heat flow curves of pastes OPC 98_G 2, OPC 96_G 4 and OPC 94_G 6 containing AF 0.74 (highest $\mathrm{Al}_{2} \mathrm{O}_{3} / \mathrm{SO}_{4}{ }^{2-}$ ratio) at $7.0 \%$ bcw. In cements containing lower gypsum amounts, $\mathrm{C}_{3} \mathrm{~A}$ hydration is advanced due to a fast sulfate depletion [24,28]. In other words, as the final 
$\mathrm{C}_{3} \mathrm{~A} / \mathrm{SO}_{3}$ ratio increases, aluminate reaction takes place earlier, as indicated by the arrows.

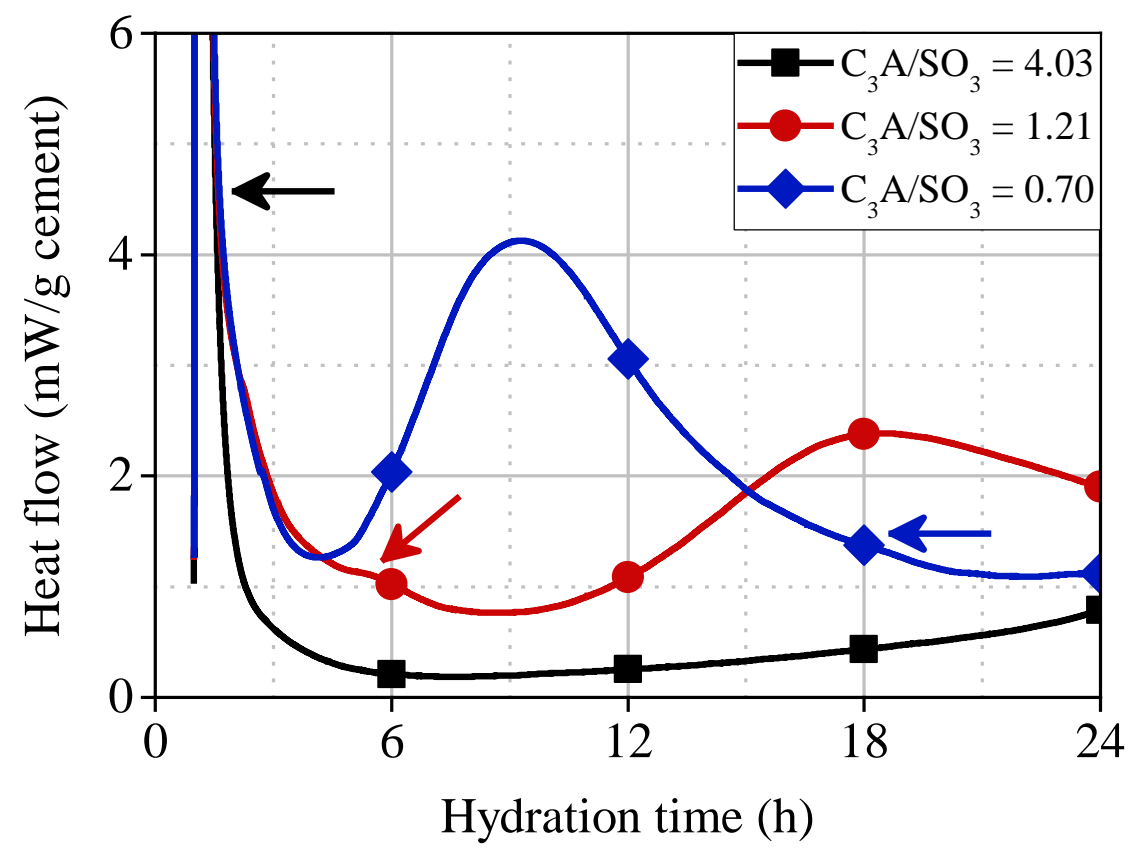

Figure 6 - Heat of hydration curves of pastes OPC 98_G 2, OPC 96_G 4 and OPC 94_G 6 produced with $\mathrm{AF} 0.74$ at $7.0 \% \mathrm{bcw}$. Arrows represent $\mathrm{C}_{3} \mathrm{~A}$ hydration in the absence of sulfates.

Paste OPC 94_G 6_AF $0.747 \%$ presents a proper sulfate balance and $\mathrm{C}_{3} \mathrm{~A}$ hydration occurs after the acceleration period of alite hydration. Therefore, higher degrees of hydration are obtained at $24 \mathrm{~h}$ (Table A.1). However, as paste OPC 96_G 4_AF 0.74 $7 \%$ is poorly sulfated, $\mathrm{C}_{3} \mathrm{~A}$ hydration is accelerated and takes place at $6 \mathrm{~h}$ approximately, retarding the onset of the main hydration peak and reducing its intensity.

Paste OPC 98_G 2_AF $0.747 \%$ is the most unfavorable case because only 0.05 mmol of $\mathrm{SO}_{4}{ }^{2-} / \mathrm{g}$ cement remains after accelerator reaction (final $\mathrm{C}_{3} \mathrm{~A} / \mathrm{SO}_{3}$ ratio equal to 4.03, Table A.1). The limited sulfate content left leads to undersulfated $\mathrm{C}_{3} \mathrm{~A}$ reactions, generating hydroxyl-AFm and monosulfoaluminate [24] during the accelerator peak. The precipitation of these phases on alite and $\mathrm{C}_{3} \mathrm{~A}$ surfaces decreases their solubility and delays their hydration, increasing induction periods, lowering reaction rates and broadening the main hydration peak. The elevated aluminum concentrations generated by undersulfated $\mathrm{C}_{3} \mathrm{~A}$ reactions and the incorporation of these ions on silicate-containing phases may also decrease the rate of alite hydration, as discussed in section 3.1 [25]. A 
small signal of silicate reaction can only be observed after $18 \mathrm{~h}$, compromising the evolution of mechanical strength of the matrix.

Figure 7 shows the influence of the final $\mathrm{C}_{3} \mathrm{~A} / \mathrm{SO}_{3}$ ratio on the main hydration peak in pastes OPC 98_G 2, OPC 96_G 4 and OPC 94_G 6 containing AF 0.60 and AF 0.74 at 5.0 and $7.0 \% \mathrm{bcw}$. Accelerator AF 0.33 was not used in this evaluation because it does not change the initial $\mathrm{C}_{3} \mathrm{~A} / \mathrm{SO}_{3}$ ratio of cements. Increasing $\mathrm{C}_{3} \mathrm{~A} / \mathrm{SO}_{3}$ ratios retard the onset of the main hydration peak and decrease reaction rates. Therefore, lower degrees of hydration are obtained at $24 \mathrm{~h}$.

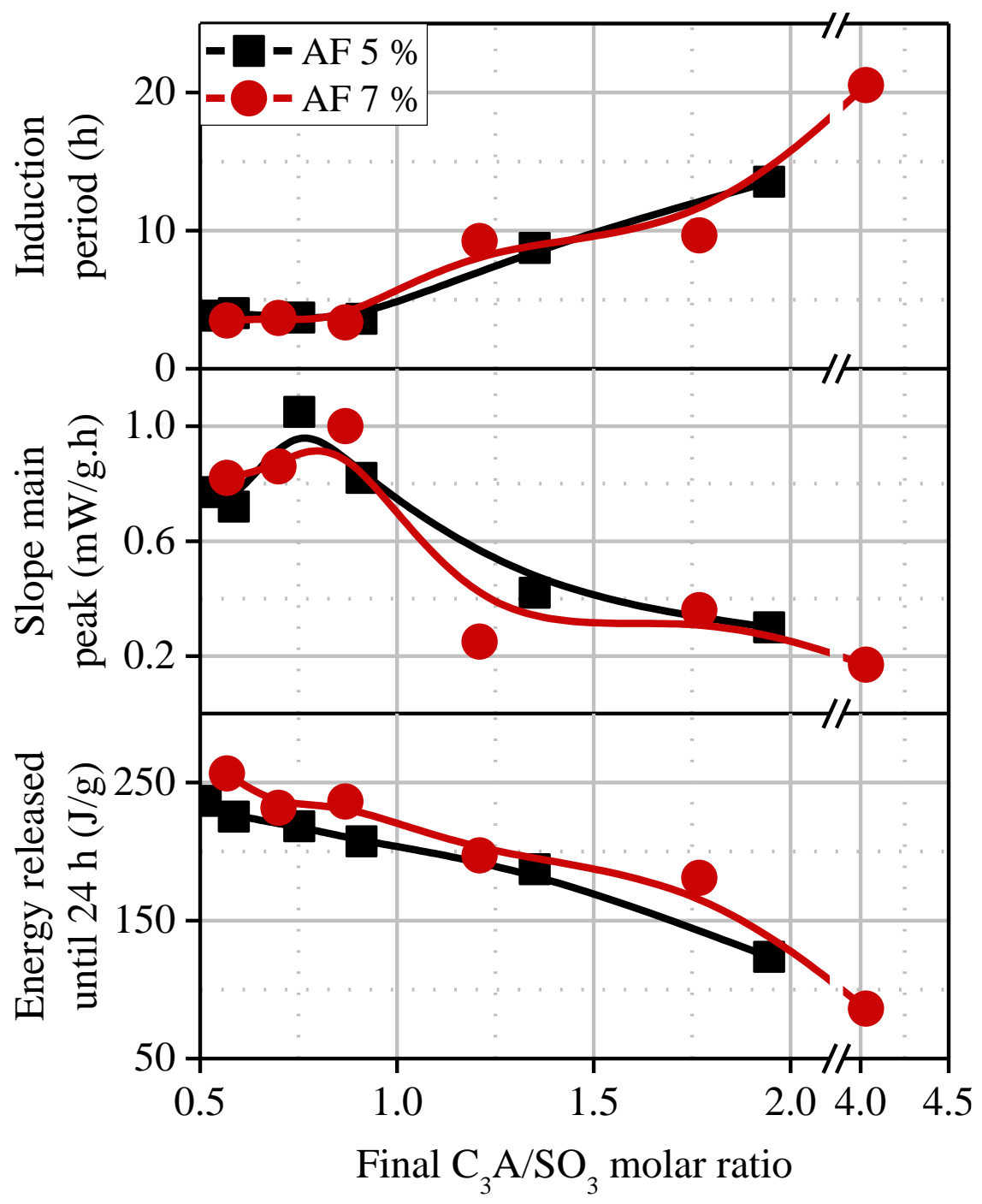


Figure 7 - Influence of the final $\mathrm{C}_{3} \mathrm{~A} / \mathrm{SO}_{3}$ ratio on the main hydration peak in pastes OPC 98_G 2, OPC 96_G 4 and OPC 94_G 6 with accelerators AF 0.60 and AF 0.74 at 5.0 and $7.0 \%$ bcw.

In the mixes evaluated, the optimal $\mathrm{C}_{3} \mathrm{~A} / \mathrm{SO}_{3}$ ratio for proper cement hydration is between 0.67 and 0.90 . Within this range, induction periods and degrees of hydration are not negatively affected and, more importantly, the main hydration peak presents the highest intensities and reaction rates. Values below 0.67 provide higher degrees of hydration in the main peak, although reaction rates and intensities are not optimal. On the contrary, values above 0.90 are absolutely detrimental for cement hydration. Induction periods are significantly longer, retarding the hardening of the paste and the development of mechanical strength.

The reactivity of the alkaline accelerator is also enhanced by larger gypsum amounts, as observed in Figure 8. Since this accelerator is based on sodium aluminate, gypsum is the only sulfate source for the formation of sulfoaluminate hydrated phases. Therefore, paste OPC 94_G 6_AK 3\%, which contains the largest gypsum amount, presents the fastest and most extensive accelerator reactions. 


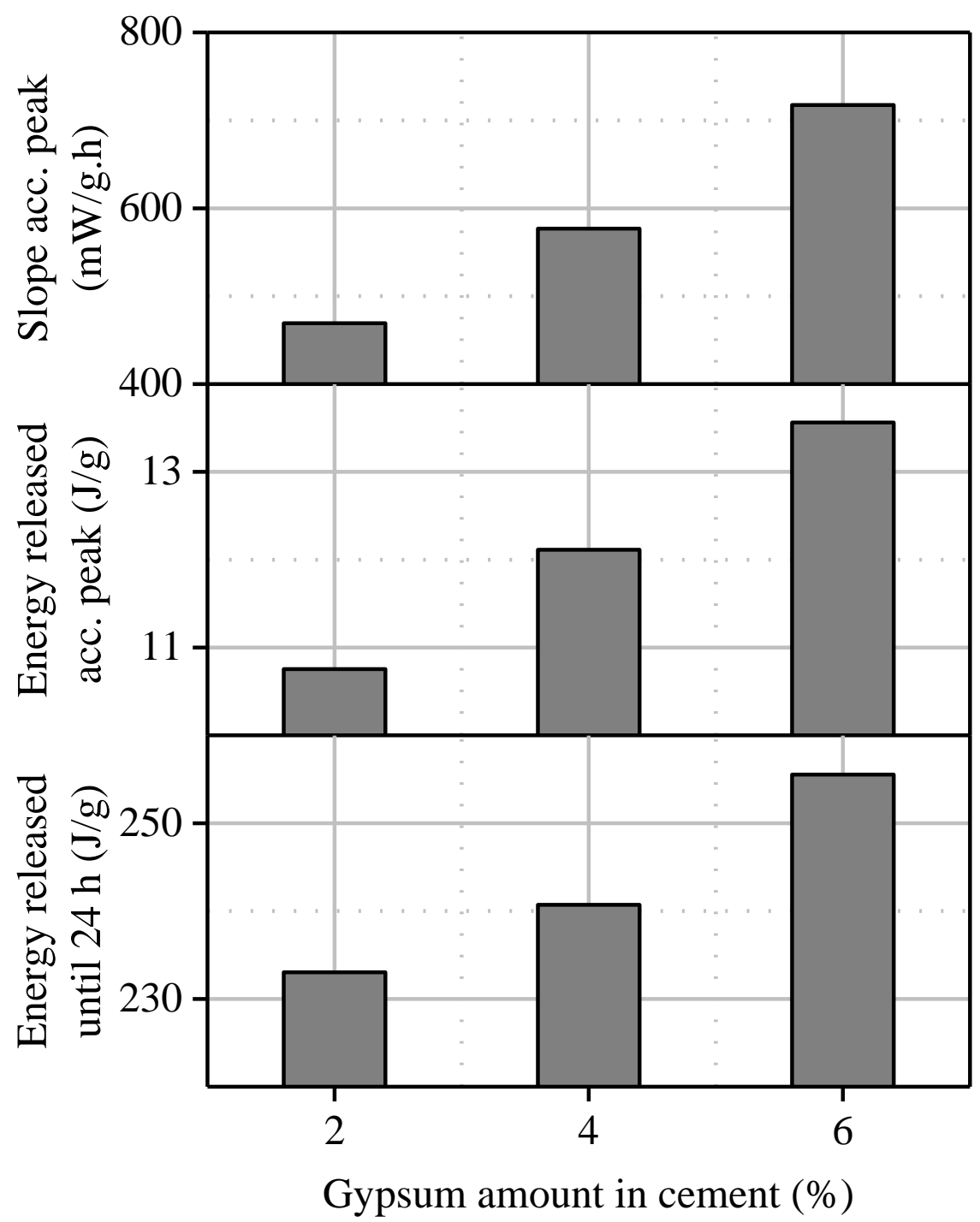

Figure 8 - Influence of gypsum amount on the reactivity of the alkaline accelerator and on the degree of hydration of the cement paste.

Pastes OPC 98_G 2_AK 3\%,OPC 96_G 4_AK 3\% and OPC 94_G 6_AK 3\% present a sharp peak during the induction period related to the renewed $\mathrm{C}_{3} \mathrm{~A}$ hydration (Figure A.1, Figure A.2, Figure A.3). The formation of AFm phases is accelerated in pastes containing lower gypsum amounts. As this process occurs before the onset of the main hydration peak, alite hydration is suppressed. Paste OPC 98_G 2_AK 3\% presents 
the lowest energy released until $24 \mathrm{~h}$ because it is undersulfated $\left(\mathrm{C}_{3} \mathrm{~A} / \mathrm{SO}_{3}\right.$ ratio equal to 7.57, Table A.1).

\subsubsection{Calcium sulfate type in cement}

The influence of the setting regulator on the hydration of pastes OPC 96_G 4 and OPC 96_H 3.38 (equivalent amounts of calcium sulfate in mol) is analyzed. Accelerator reaction rates are more than $20 \%$ higher in pastes containing hemihydrate (66 and $55 \%$ higher when AF $0.747 \%$ and AK 3\% are employed, respectively), as presented in Figure 9. Since calcium sulfate hemihydrate is more soluble than gypsum, it provides a faster increase in sulfate ions concentration in the liquid phase. The use of hemihydrate is particularly important when accelerator is added at $7.0 \% \mathrm{bcw}$ and for accelerators with $\mathrm{Al}_{2} \mathrm{O}_{3} / \mathrm{SO}_{4}{ }^{2-}$ ratios equal to 0.74 .

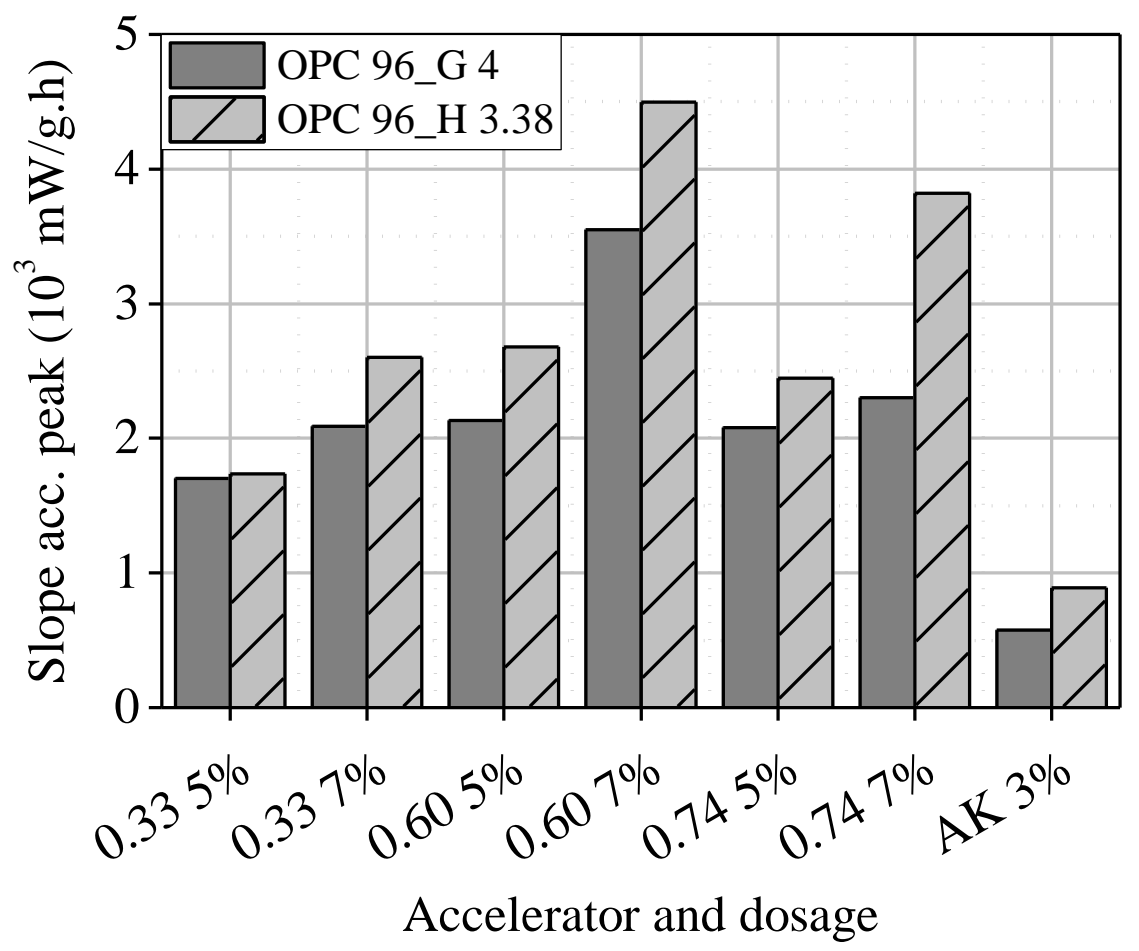

Figure 9 - Accelerator reaction rates in pastes OPC 96_G 4 and OPC 96_H 3.38. 
Figure 10 correlates the energy released in the accelerator peak and the $\mathrm{Al}^{3+}$ content from alkali-free accelerators in pastes OPC 96_G 4 and OPC 96_H 3.38. A linear regression properly fits those parameters, providing $\mathrm{R}^{2}$ values higher than 0.985 in all the cases. The angular coefficient represents the rate of ettringite formation [24], confirming that hemihydrate improves accelerator reactivity. Values of linear and angular coefficients are presented in Table 11.

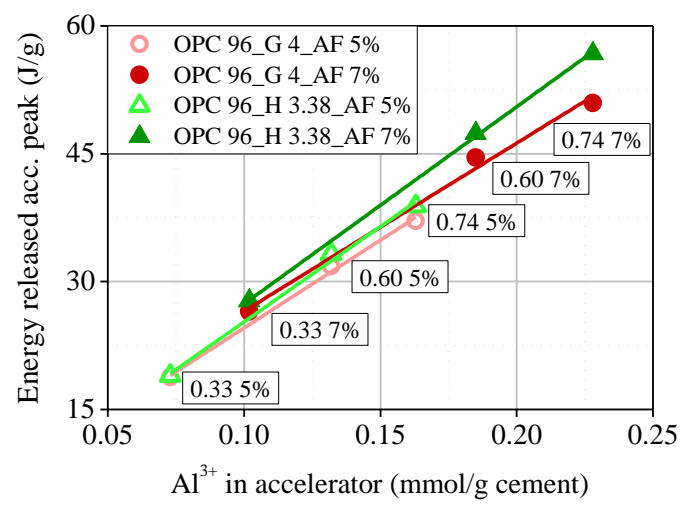

Figure 10 - Correlations between the energy released in the accelerator peak and $\mathrm{Al}^{3+}$ content in accelerator in pastes OPC 96_G 4 and OPC 96_H 3.38 containing alkali-free accelerators.

Table 11 - Coefficients $a$ and $b$ for the linear regressions obtained $(y=a+b x)$.

\begin{tabular}{ccc}
\hline Paste & a & b \\
\hline OPC 96_G 4_AF 5\% & 3.97 & 205.9 \\
\hline OPC 96_G 4_AF 7\% & 6.81 & 197.2 \\
\hline OPC 96_H 3.38_AF 5\% & 2.90 & 223.7 \\
\hline OPC 96_H 3.38_AF 7\% & 4.27 & 231.2 \\
\hline
\end{tabular}

Linear coefficients should be close to zero considering ettringite as the only hydrate formed by accelerator reaction. However, linear coefficients are not zero, indicating that other exothermic processes occur when accelerators are added. They might be corresponded to alite dissolution caused by formic acid contained in accelerators [12] and to the formation of hydroxyl-AFm by $\mathrm{C}_{3} \mathrm{~A}$ hydration in the absence of sulfates $[24,28]$. Since formic acid concentration is identical in all formulations, the heat generated by the acid dissolution must be equal in pastes containing accelerator dosages of either 5.0 or $7.0 \%$ bcw. Therefore, as the y-intercepts are lower in pastes OPC 96_H 3.38, the 
formation of hydroxyl-AFm during the accelerator peak is reduced if hemihydrate is the setting regulator, due to the higher concentration of sulfate ions available in the liquid phase.

The fast consumption of sulfate ions in pastes OPC 96_H 3.38 by accelerator reaction advances further $\mathrm{C}_{3} \mathrm{~A}$ hydration, as also observed in [24]. Consequently, a shoulder related to the formation of $\mathrm{AFm}$ phases in pastes containing $\mathrm{Al}^{3+}$ additions above $0.163 \mathrm{mmol} / \mathrm{g}$ cement (AF 0.60 at $7.0 \%$ and $\mathrm{AF} 0.74$ at 5.0 and $7.0 \%$ ) may be observed around 5 and $6 \mathrm{~h}$ of hydration in Figure A.4. The accelerated formation of AFm phases reduces reaction rates during the acceleration period and degrees of hydration until $24 \mathrm{~h}$ [11], as observed in Figure 11. A similar behavior is observed in the paste containing the alkaline accelerator.

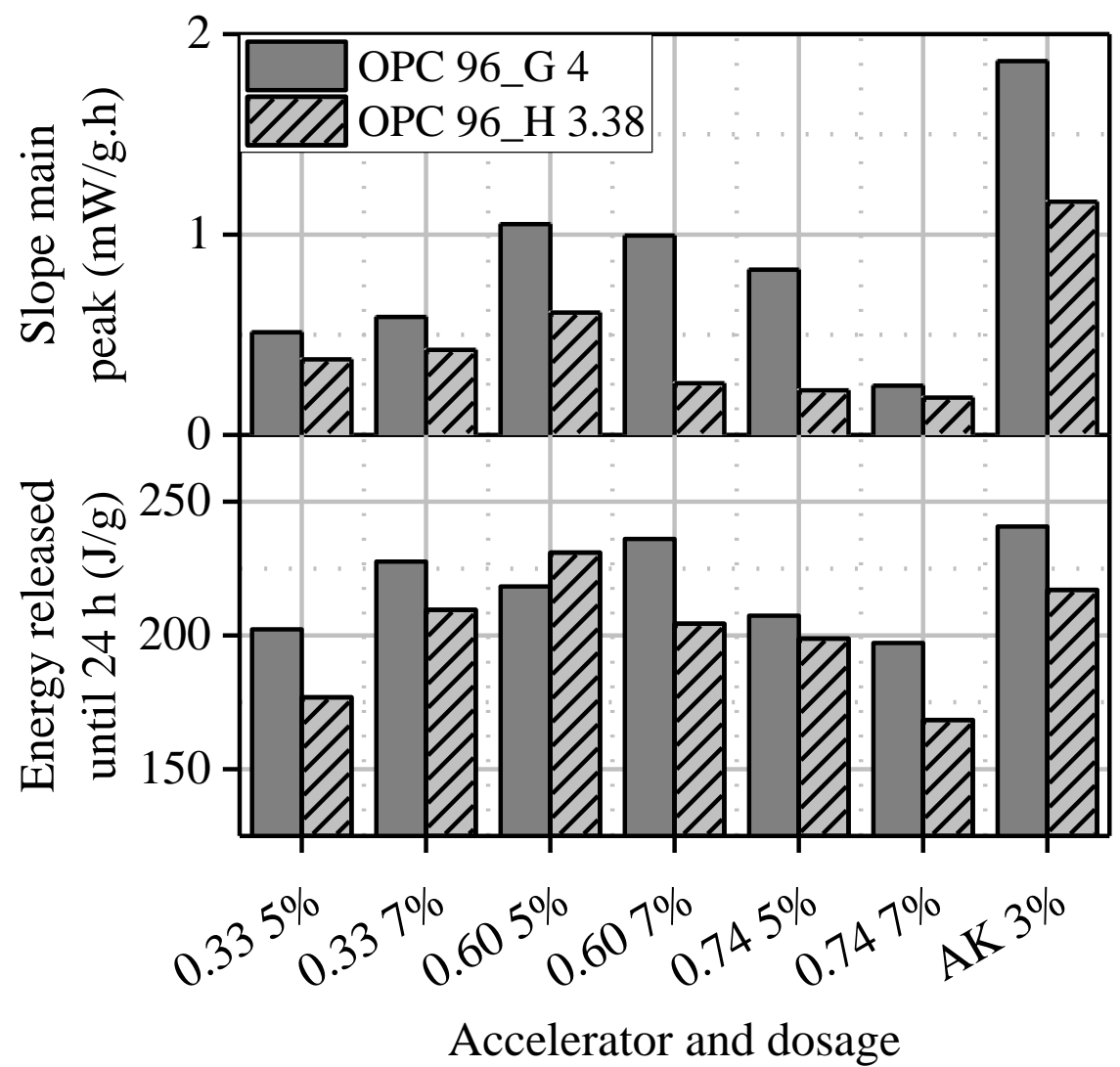

Figure 11 - Slope of the main hydration peak and energy released until $24 \mathrm{~h}$ in pastes OPC 96_G 4 and OPC 96 H 3.38. 


\subsection{5. $\mathrm{C}_{3} \mathrm{~A}$ content in cement}

The influence of $\mathrm{C}_{3} \mathrm{~A}$ content on the hydration behavior of pastes OPC 96_G 4 and SRC 96_G 4 is analyzed in Figure 12. Accelerator reactivity is enhanced in pastes SRC 96_G 4. Since this cement contains only $1.6 \%$ of $\mathrm{C}_{3} \mathrm{~A}$ (approximately $28 \%$ of the amount in OPC 96_G 4), initial sulfate consumption proceeds at a minor extent and more sulfate ions are available for accelerator reaction. Therefore, accelerator reaction rates and the energies released during this process are around $15 \%$ and $10 \%$ higher in SRC pastes, respectively. 


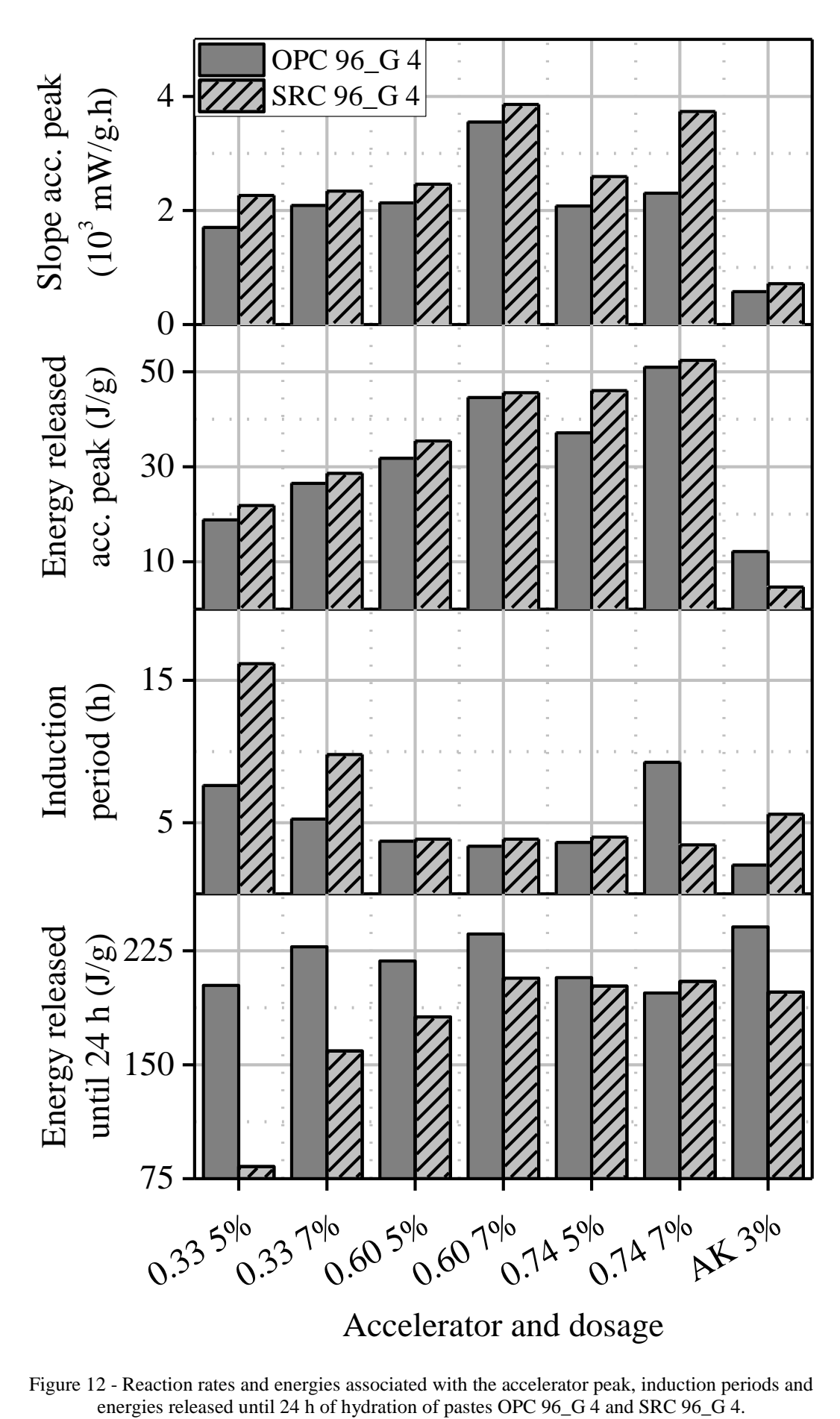


The SRC clinker is coarser than the OPC clinker and induction periods are extended in SRC 96_G 4 pastes. Accelerator AF 0.33 leads to the longest retardation on the onset of the main hydration peak because it consumes the lowest amount of $\mathrm{Ca}^{2+}$ ions from de liquid phase, resulting in low rates of alite dissolution. Furthermore, $\mathrm{C}_{3} \mathrm{~A}$ hydration in pastes SRC 96_G 4_AF 0.335 and 7\% is retarded due to their low final $\mathrm{C}_{3} \mathrm{~A} / \mathrm{SO}_{3}$ ratios. Consequently, their degrees of hydration are greatly reduced.

Accelerators AF 0.60 and AF 0.74 consume more calcium and sulfate ions than AF 0.33. This favors alite and gypsum dissolutions, increases the rates of nucleation and growth of hydrates and reduces induction periods. Besides, the retardation in $\mathrm{C}_{3} \mathrm{~A}$ hydration is not so severe because these accelerators lead to higher final $\mathrm{C}_{3} \mathrm{~A} / \mathrm{SO}_{3}$ ratios than AF 0.33. The most synergistic effect is paste SRC 96_G 4_AF $0.747 \%$, with a final $\mathrm{C}_{3} \mathrm{~A} / \mathrm{SO}_{3}$ ratio equal to 0.41 (while the equivalent $\mathrm{OPC}$ paste has a final $\mathrm{C}_{3} \mathrm{~A} / \mathrm{SO}_{3}$ ratio equal to 1.21 , which is not adequate for strength development). The accelerated undersulfated $\mathrm{C}_{3} \mathrm{~A}$ hydration is avoided in pastes SRC 96_G 4 due to their proper sulfate balance.

Paste SRC 96_G 4_AK 3\% presents the same overall hydration behavior as OPC 96_G 4_AK 3\%. The accelerated C3A hydration in SRC 96_G 4_AK 3\% occurs between 3.2 and $5 \mathrm{~h}$ and the energy associated with this process corresponds to $11.2 \mathrm{~J} / \mathrm{g}$ cement (Figure A.8). However, $\mathrm{C}_{3} \mathrm{~A}$ hydration takes place between 1.8 and $3.4 \mathrm{~h}$ in the equivalent OPC paste and releases an energy equal to $23.0 \mathrm{~J} / \mathrm{g}$ cement (Figure A.2). The lower $\mathrm{C}_{3} \mathrm{~A}$ content and the resulting lower $\mathrm{C}_{3} \mathrm{~A} / \mathrm{SO}_{3}$ ratio in SRC 96_G 4_AK 3\% are responsible for the retardation and the lower intensity of undersulfated $\mathrm{C}_{3} \mathrm{~A}$ reactions.

\subsubsection{Limestone filler in cement}

Figure 13 shows the energy released by accelerator reaction in pastes OPC 96_G 4, OPC 94_G 6 and OPC 96_H 3.38 with and without limestone filler. Results of pastes containing limestone filler are presented as determined and normalized by the content of clinker plus calcium sulfate ( $87 \%$ by mass). 


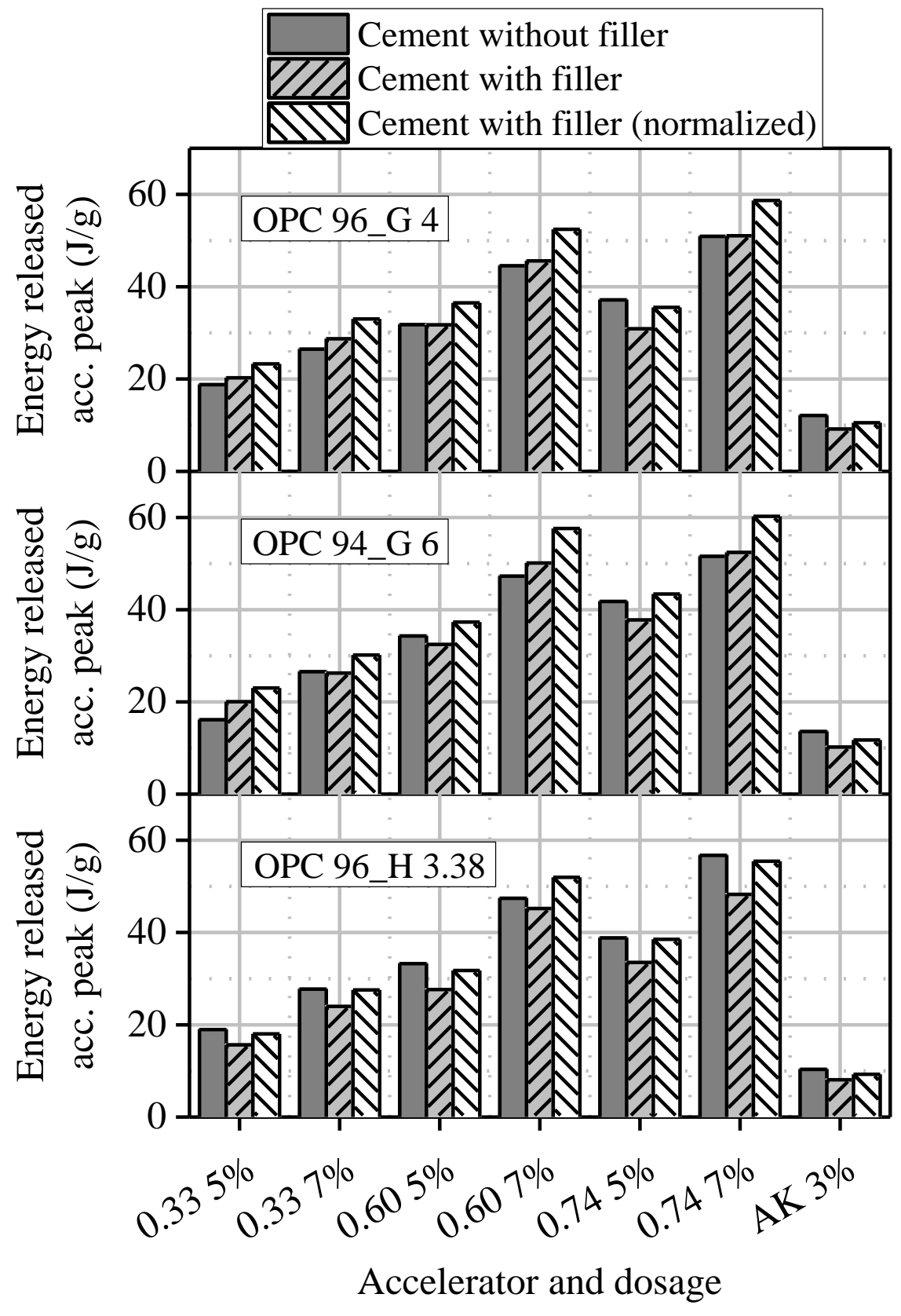

Figure 13 - Energy released during the accelerator peak in pastes OPC 96_G 4, OPC 94_G 6 and OPC 96_H 3.38 with and without limestone filler. 
Analyzing the results as determined, the energy released by accelerator reaction in pastes OPC 96_G 4_F and OPC 94_G 6_F is not significantly different from the equivalent pastes without limestone filler (the difference falls within the $\pm 8 \%$ interval). However, considering the normalized results, it is clear that accelerator reactivity is enhanced by this addition. Increments of $20 \%$ in the energy released in the accelerator peak in pastes containing limestone filler and accelerators AF 0.60 and 0.74 are observed. Normalized results in pastes OPC 96_H 3.38_F present the same tendency, although the influence of limestone filler is minor when hemihydrate is the calcium sulfate source.

Limestone filler competes with gypsum to retard $\mathrm{C}_{3} \mathrm{~A}$ hydration $[29,30]$ and may also control the reaction of $\mathrm{Al}^{3+}$ from the accelerator, forming hemi and monocarboaluminate [12]. This phase is more stable than other AFm phases at room temperature and indirectly stabilizes ettringite [31]. Therefore, limestone filler improves accelerator reactivity in sprayed concrete applications, as indicated in $[1,5]$.

Results suggest a synergistic effect between limestone filler and alkali-free accelerators, mainly for $\mathrm{Al}^{3+}$ additions above $0.163 \mathrm{mmol} / \mathrm{g}$ cement and for accelerators having $\mathrm{Al}_{2} \mathrm{O}_{3} / \mathrm{SO}_{4}^{2-}$ ratios above 0.60 employed at $7.0 \% \mathrm{bcw}$. The acidic nature of alkalifree accelerators favors limestone dissolution, thereby enhancing $\mathrm{Al}^{3+}$ reaction, which is limited by gypsum dissolution in CEM I pastes. As hemihydrate is more soluble than gypsum, it inhibits calcium carbonate dissolution by the common ion $\left(\mathrm{Ca}^{2+}\right)$ effect, limiting its efficiency.

Limestone filler may also act as a nucleation site for the precipitation of aluminate hydrated phases formed by accelerator reaction, as observed by SEM imaging. Figure 14.a and Figure 14.b present the microstructure of pastes OPC 96_G 4_F_AF $0.607 \%$ and OPC 96_G 4_F_AK 3\% at 15 min of hydration, respectively. A limestone particle is indicated by an ' $\mathrm{L}$ ' in each picture (identified by the EDS results 1 and 3). 


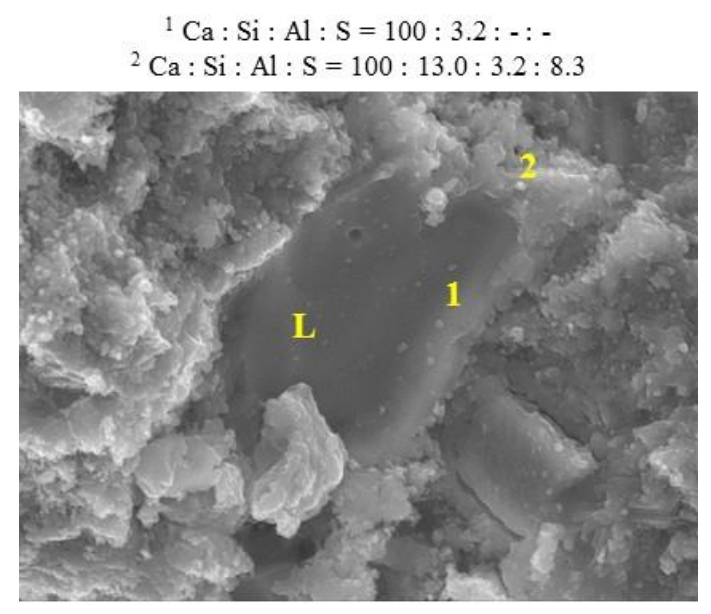

(a)

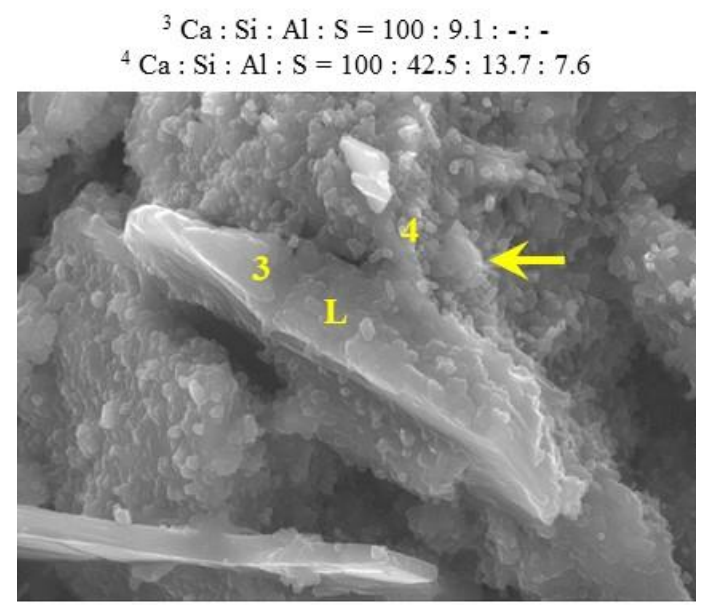

(b)

Figure 14 - Paste OPC 96_G 4_F_AF $0.607 \%$ at 15 min (a) with corresponding EDS spectra 1 and 2 and paste OPC 96_G 4_F_AK 3\% at 15 min (b) with corresponding EDS spectra 3 and 4.

In Figure 14.a, the limestone particle is embedded in the microstructure of the matrix. In the region corresponding to EDS 2, the aluminate hydrates precipitated on the particle are composed mainly by $\mathrm{AFt}$ phases, since the $\mathrm{Al} / \mathrm{S}$ ratio is 0.39 (below 0.667 , which is the $\mathrm{Al} / \mathrm{S}$ ratio in pure ettringite). This is expected, since the alkali-free accelerator contains sulfate ions and ettringite is the main hydrate formed by its reaction.

On the contrary, the aluminate hydrates precipitated on the limestone surface when the alkaline accelerator is employed (Figure 14.b) present an $\mathrm{Al} / \mathrm{S}$ ratio equal to 1.8 
(EDS 4). Hence, they might be composed mainly by AFm phases (in pure monosulfoaluminate, the $\mathrm{Al} / \mathrm{S}$ ratio is equal to 2 ). In addition, some hydrates surrounding the limestone particle are plate-like crystals (such as in the region identified by an arrow), which are also characteristic of AFm phases [17,32].

Figure 15 shows the total energy released until $24 \mathrm{~h}$ in the pastes analyzed. Normalized results show the beneficial use of limestone filler on the overall cement hydration, mainly in pastes containing $\mathrm{AF} 0.60$ and $\mathrm{AF} 0.74$ (high $\mathrm{Al}^{3+}$ concentrations and high final $\mathrm{C}_{3} \mathrm{~A} / \mathrm{SO}_{3}$ ratios). Besides the physical effect of clinker dilution that increases the space for the precipitation of hydrates [33], limestone filler avoids accelerated undersulfated $\mathrm{C}_{3} \mathrm{~A}$ reactions and alite hydration may proceed normally. As a result, degrees of hydration are around $6 \%$ higher in pastes containing this addition. 


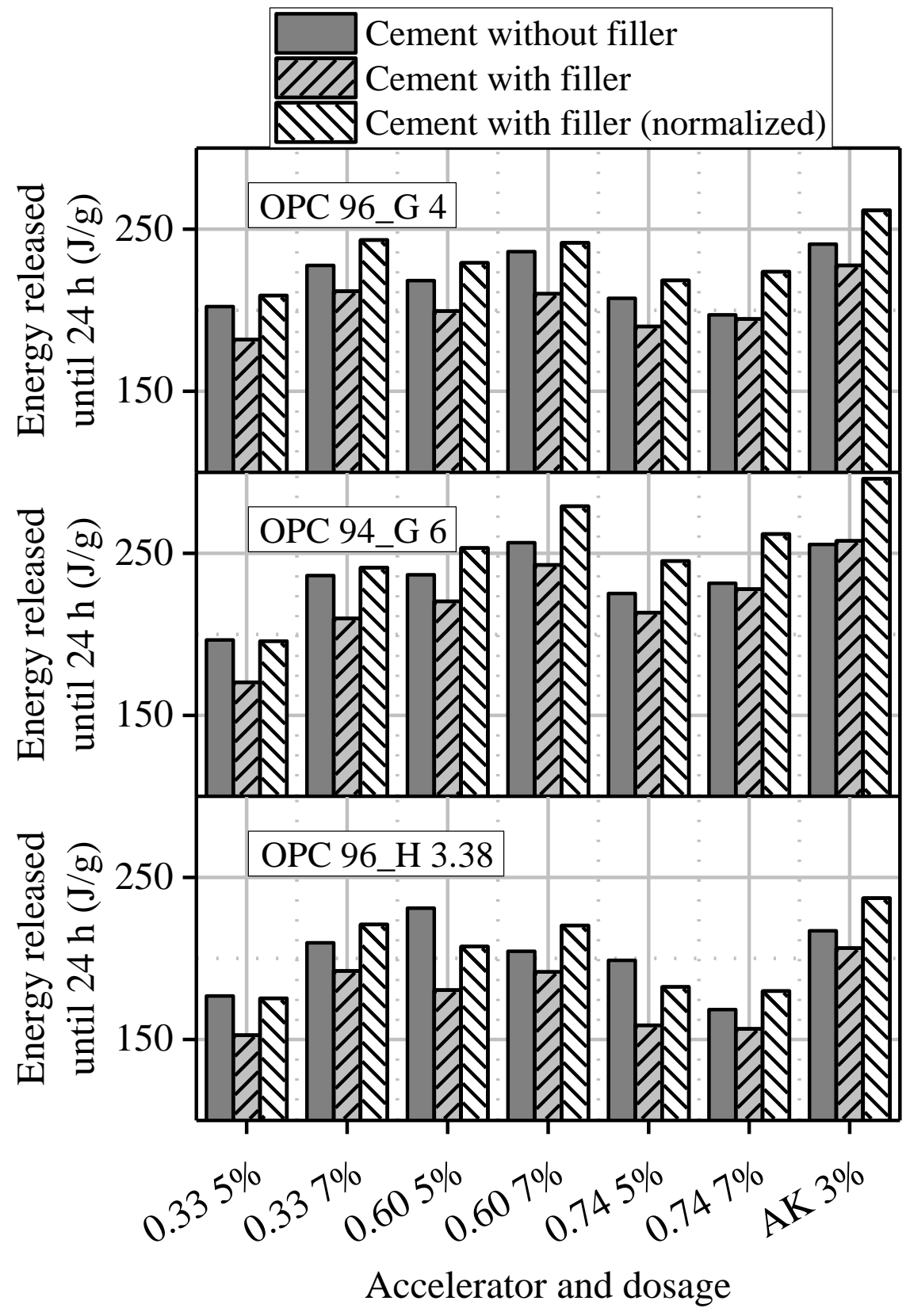

Figure 15 - Energy released until 24 h in pastes OPC 96_G 4, OPC 94_G 6 and OPC 96_H 3.38 with and without limestone filler. 
The alkaline accelerator reactivity is slightly reduced by the use of limestone filler because this addition replaces part of the calcium sulfate contained in cement initially. As discussed in section 3.2.3, gypsum amount in cement is a key parameter to control the reaction of this accelerator. However, limestone filler compensates the fast sulfate depletion in alkaline accelerated pastes by controlling $\mathrm{C}_{3} \mathrm{~A}$ hydration, increasing their degree of hydration.

\subsubsection{Summary of results}

Table 12 presents a summary of the parameters evaluated in this study and their influence on the overall hydration behavior of accelerated cement pastes. Ascending arrows indicate an increase in the parameter analyzed and descending arrows, a decrease.

Table 12 - Summary of the variables evaluated and their influence on hydration kinetics.

\begin{tabular}{|c|c|c|c|c|c|}
\hline \multirow[b]{2}{*}{ Parameter } & \multirow[b]{2}{*}{ Variation } & \multirow{2}{*}{ Refer to } & \multicolumn{3}{|c|}{ Effect on hydration kinetics } \\
\hline & & & $\begin{array}{c}\text { Accelerator } \\
\text { peak }\end{array}$ & $\begin{array}{c}\begin{array}{c}\text { Induction } \\
\text { period }\end{array} \\
\end{array}$ & Main peak \\
\hline $\begin{array}{c}\mathrm{Al}^{3+} \text { in } \\
\text { accelerator / } \\
\text { accelerator } \\
\text { dosage }\end{array}$ & Increase & $\begin{array}{c}\text { Section: } 3.2 .1 \\
\text { Figure: Figure } \\
4\end{array}$ & & $\begin{array}{c}\text { Depends on } \\
\mathrm{Al}_{2} \mathrm{O}_{3} / \mathrm{SO}_{4}{ }^{2-} \\
\text { ratio and final } \\
\mathrm{C}_{3} \mathrm{~A}_{/} / \mathrm{SO}_{3} \text { ratio }\end{array}$ & $\begin{array}{l}\text { Depends on } \\
\mathrm{Al}_{2} \mathrm{O}_{3} / \mathrm{SO}_{4}{ }^{2-} \\
\text { ratio and fina } \\
\mathrm{C}_{3} \mathrm{~A} / \mathrm{SO}_{3} \text { ratic }\end{array}$ \\
\hline $\begin{array}{c}\mathrm{Al}_{2} \mathrm{O}_{3} / \mathrm{SO}_{4}^{2-} \\
\text { ratio in } \\
\text { accelerator }\end{array}$ & $\begin{array}{c}\text { Increase } \\
\text { (above } \\
0.60 \text { ) }\end{array}$ & $\begin{array}{l}\text { Section: } 3.2 .2 \\
\text { Figure: Figure } \\
5\end{array}$ & - & Increase & \\
\hline $\begin{array}{l}\text { Gypsum } \\
\text { amount }\end{array}$ & Increase & $\begin{array}{c}\text { Section: } 3.2 .3 \\
\text { Figures:Figure } \\
\text { 4, Figure } 8\end{array}$ & & Increase & \\
\hline Hemihydrate & Increase & $\begin{array}{c}\text { Section: } 3.2 .4 \\
\text { Figures: } \\
\text { Figure 9, } \\
\text { Figure } 11\end{array}$ & & Decrease & \\
\hline $\mathrm{C}_{3} \mathrm{~A}$ content & Increase & $\begin{array}{c}\text { Section: } 3.2 .5 \\
\text { Figure: Figure } \\
12\end{array}$ & & Decrease & \\
\hline
\end{tabular}




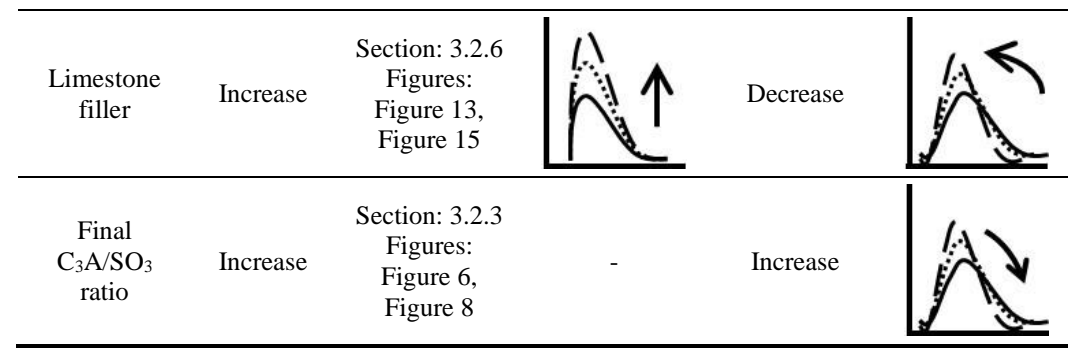

\section{Conclusions}

The following conclusions may be drawn from the results obtained in this experimental program:

- Alkali-free and alkaline accelerators reactions lead to the fast formation of sulfoaluminate hydrates, mainly ettringite. The higher the $\mathrm{Al}^{3+}$ content incorporated in the paste by accelerators, the larger the amount of sulfoaluminate hydrates precipitated.

- Gypsum content in cement is a key parameter to balance sulfate consumption by accelerators and to control accelerator reactivity. Large gypsum amounts counterbalance high $\mathrm{Al}_{2} \mathrm{O}_{3} / \mathrm{SO}_{4}{ }^{2-}$ ratios in accelerators and avoid uncontrolled $\mathrm{C}_{3} \mathrm{~A}$ reactions caused by sulfate depletion. As a result, alite hydrates properly and higher degrees of hydration are obtained until $24 \mathrm{~h}$.

- The setting regulator type plays an important role in the overall hydration process. Calcium sulfate hemihydrate saturates the mixing water with calcium and sulfate ions faster than gypsum, which increases accelerator reactivity and leads to faster rates of sulfoaluminate hydrates precipitation. The fast consumption of sulfate by accelerators results in accelerated $\mathrm{C}_{3} \mathrm{~A}$ reactions, with consequent formation of $\mathrm{AFm}$ phases. This process fills up the space available in the paste before the onset of the main hydration peak, decreasing the rate and extent of alite hydration. The combination of hemihydrate and accelerators with high $\mathrm{Al}_{2} \mathrm{O}_{3} / \mathrm{SO}_{4}{ }^{2-}$ ratios is not adequate for proper cement hydration.

- A combination of gypsum and hemihydrate may be beneficious for cement hydration. Hemihydrate increases accelerator reactivity and sulfate left after accelerator reaction (in the form of gypsum) controls $\mathrm{C}_{3} \mathrm{~A}$ hydration. Therefore, initial strength gain rate 
should be faster and alite hydration could proceed normally, achieving higher degrees of hydration.

- Cements containing low $\mathrm{C}_{3} \mathrm{~A}$ contents enhance accelerator reactivity because more sulfate is available for accelerator reaction. In pastes produced with SRC cements, the accelerated formation of AFm phases is avoided and alite dissolution is favored. On the other hand, induction periods are longer depending on accelerator type and the evolution of mechanical strength until $24 \mathrm{~h}$ may be compromised.

- Limestone filler improves accelerator reactivity when gypsum is the calcium sulfate source. Calcium carbonate reacts with $\mathrm{Al}^{3+}$ from accelerator, forming hemi and monocarboaluminate, and act as a nucleation site for the precipitation of sulfoaluminated hydrated phases. Besides, it compensates the fast sulfate depletion caused by elevated accelerator dosages and avoids accelerated undersulfated $\mathrm{C}_{3} \mathrm{~A}$ reactions. As a result, alite hydration proceeds normally and higher degrees of hydration are achieved, when compared to CEM I pastes.

- Accelerators characterized by an $\mathrm{Al}_{2} \mathrm{O}_{3} / \mathrm{SO}_{4}{ }^{2-}$ ratio equal to 0.33 (similar to ettringite) do not consume sulfate ions from the liquid phase and the initial $\mathrm{C}_{3} \mathrm{~A} / \mathrm{SO}_{3}$ ratio in cement is not altered. Therefore, unfavorable kinetics and mechanisms of cement hydration are avoided, increasing the rate and extension of alite hydration. However, ratios above 0.74 lead to a fast sulfate depletion and to accelerated undersulfated $\mathrm{C}_{3} \mathrm{~A}$ reactions. This process limits the extension of alite hydration and may be detrimental for proper strength evolution.

- The final $\mathrm{C}_{3} \mathrm{~A} / \mathrm{SO}_{3}$ ratio in accelerated pastes may predict the cement hydration behavior. This value should be kept between 0.67 and 0.90 in CEM I pastes containing gypsum and alkali-free accelerators to provide proper induction periods (below $4 \mathrm{~h}$ after accelerator addition) and alite hydration rates.

- As a final recommendation, the selection of materials for an adequate compatibility between cement and accelerator should be based on the final $\mathrm{C}_{3} \mathrm{~A} / \mathrm{SO}_{3}$ ratio of the paste. Calcium sulfate amount in cement needs to be larger than $4 \%$ and limestone filler should be employed. $\mathrm{Al}^{3+}$ supplied by accelerator should be in the range between 0.12 and $0.18 \mathrm{mmol} / \mathrm{g}$ cement, preferentially combining low $\mathrm{Al}^{3+}$ concentrations and high dosages of accelerator for proper dispersion of these ions in the matrix. Finally, the $\mathrm{Al}_{2} \mathrm{O}_{3} / \mathrm{SO}_{4}{ }^{2-}$ ratio in accelerator should be between 0.33 and 0.60 . 


\section{Acknowledgements}

The first author would like to thank CAPES (CAPES Foundation. Ministry of Education of Brazil, process 2726/13-0) for the scholarship granted. This work was financially supported by Centro para el Desarrollo Industrial (CDTi) and Ministerio de Economía y Competitividad (projects IDI-20130248 and RTC-2015-3185-4). Thanks are extended to Industrias Químicas del Ebro for technical support and to Cementos Molins for providing clinker samples.

\section{APPENDIX}

Heat of hydration curves of all the pastes obtained by isothermal calorimetry at 20 ${ }^{\circ} \mathrm{C}$ are shown from Figure A.1 to Figure A.8, grouped by cement type. Figures identified by ' $\mathrm{a}$ ' represent the curve from 0 to $24 \mathrm{~h}$ and figures identified by ' $\mathrm{b}$ ' show a zoom of the heat of hydration curve from 1.0 to $1.5 \mathrm{~h}$, corresponding to the accelerator peak. The characteristic points of the heat flow curves are summarized in Table A.1 and the conclusions derived from each variable analyzed are presented from sections 3.2.1 to 3.2.7. The curves of the reference paste were not considered in this analysis due to the significant retardation caused by the superplasticizer. 


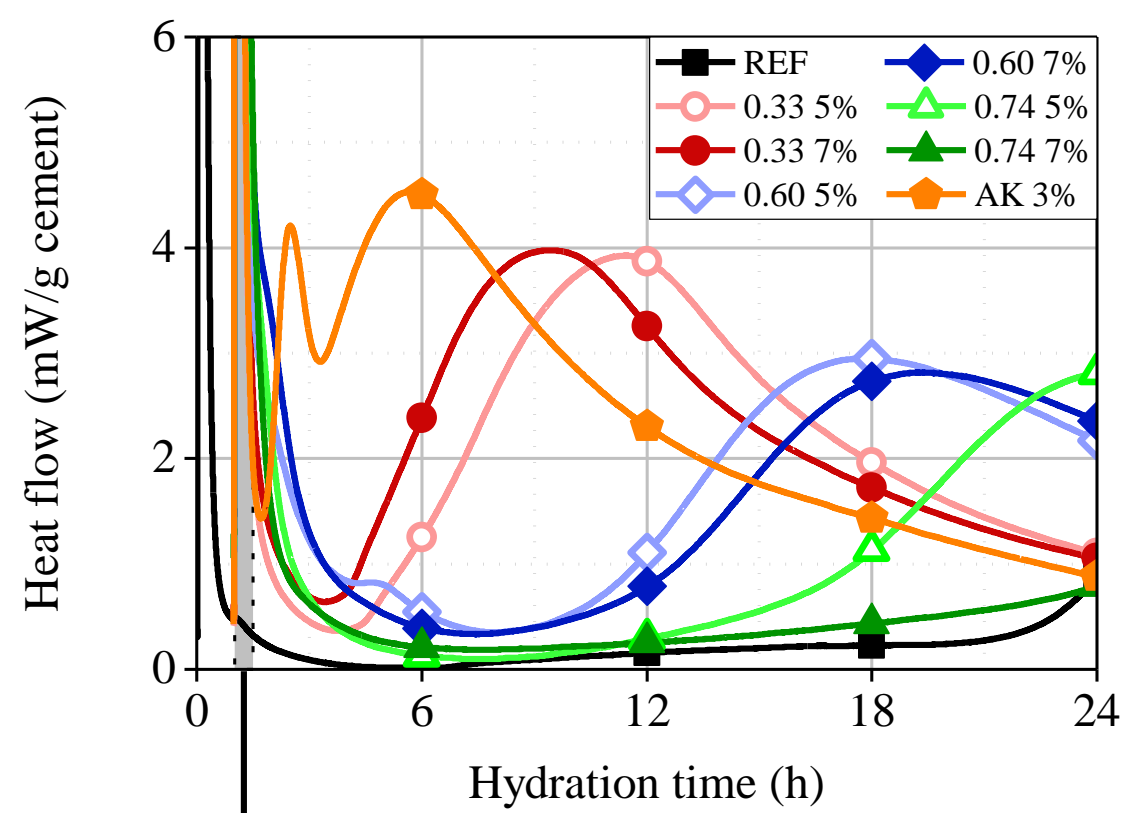

(a)

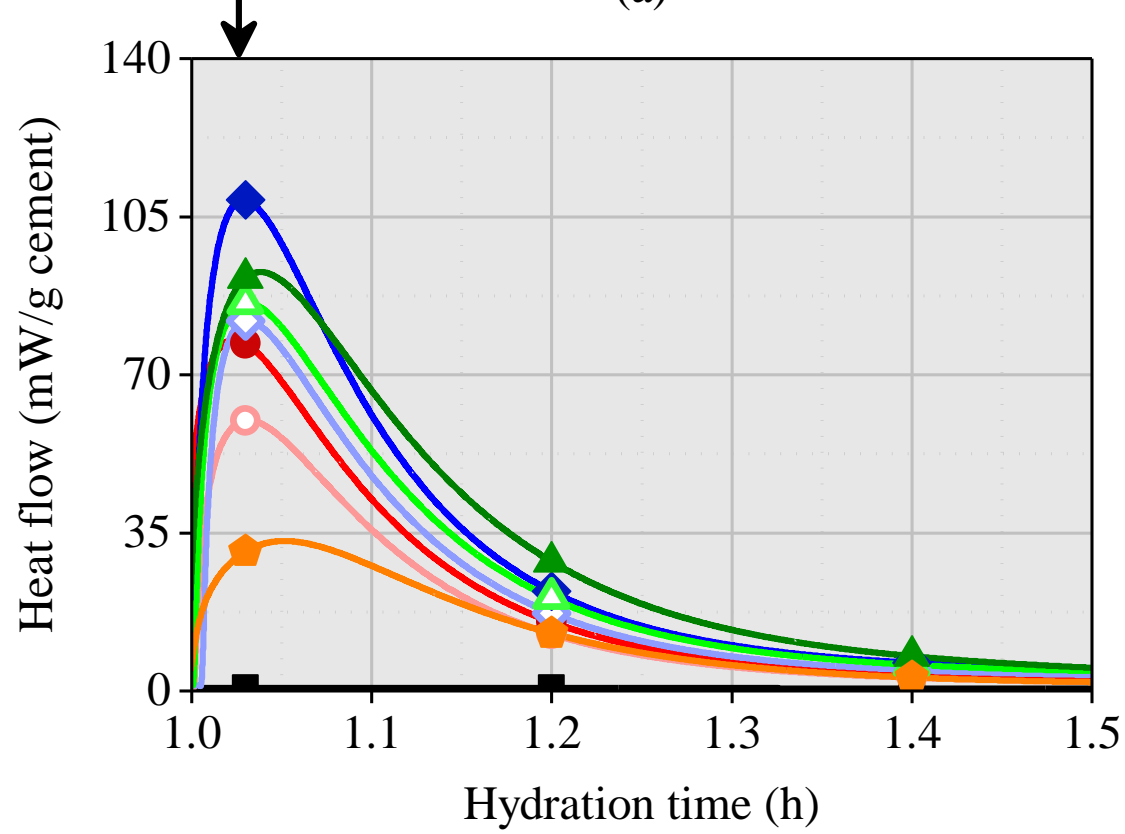

(b)

Figure A.1 - Heat flow curves of pastes OPC 98_G 2 from 0 to $24 \mathrm{~h}$ (a) and from 1.0 to $1.5 \mathrm{~h}$ (b) 


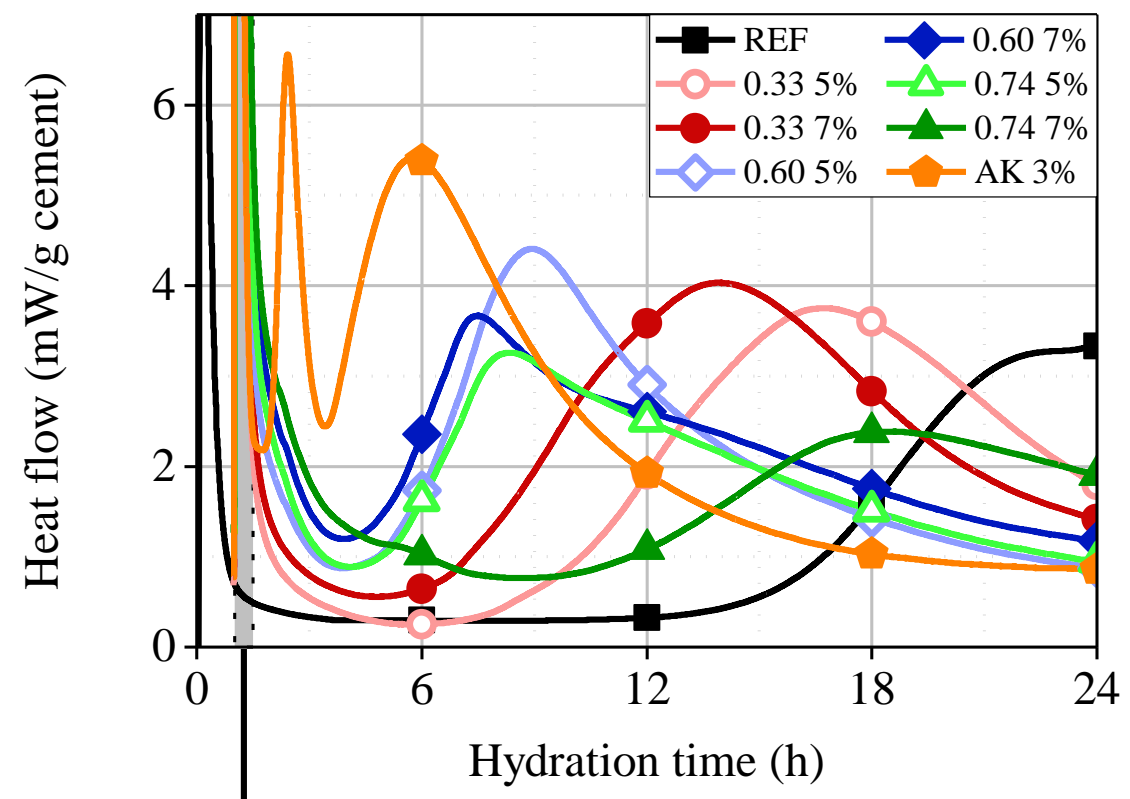

(a)

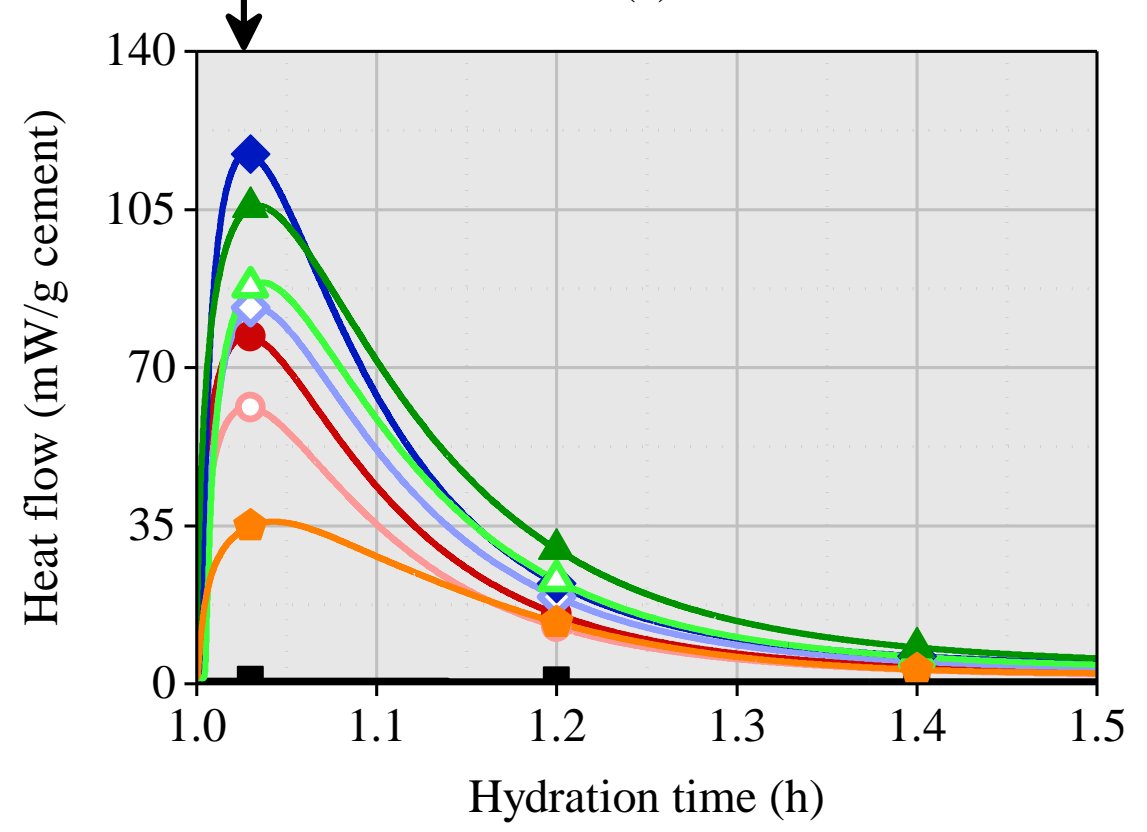

(b)

Figure A.2 - Heat flow curves of pastes OPC 96_G 4 from 0 to $24 \mathrm{~h}$ (a) and from 1.0 to $1.5 \mathrm{~h}$ (b). 


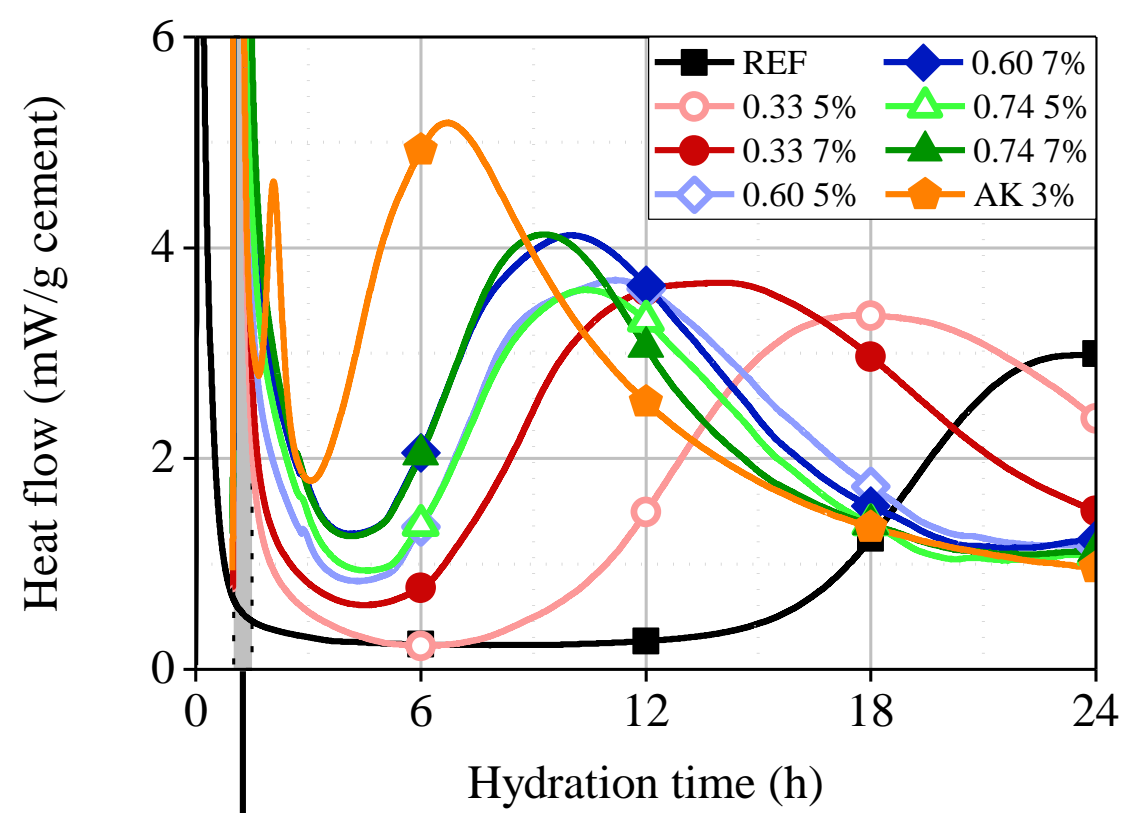

(a)

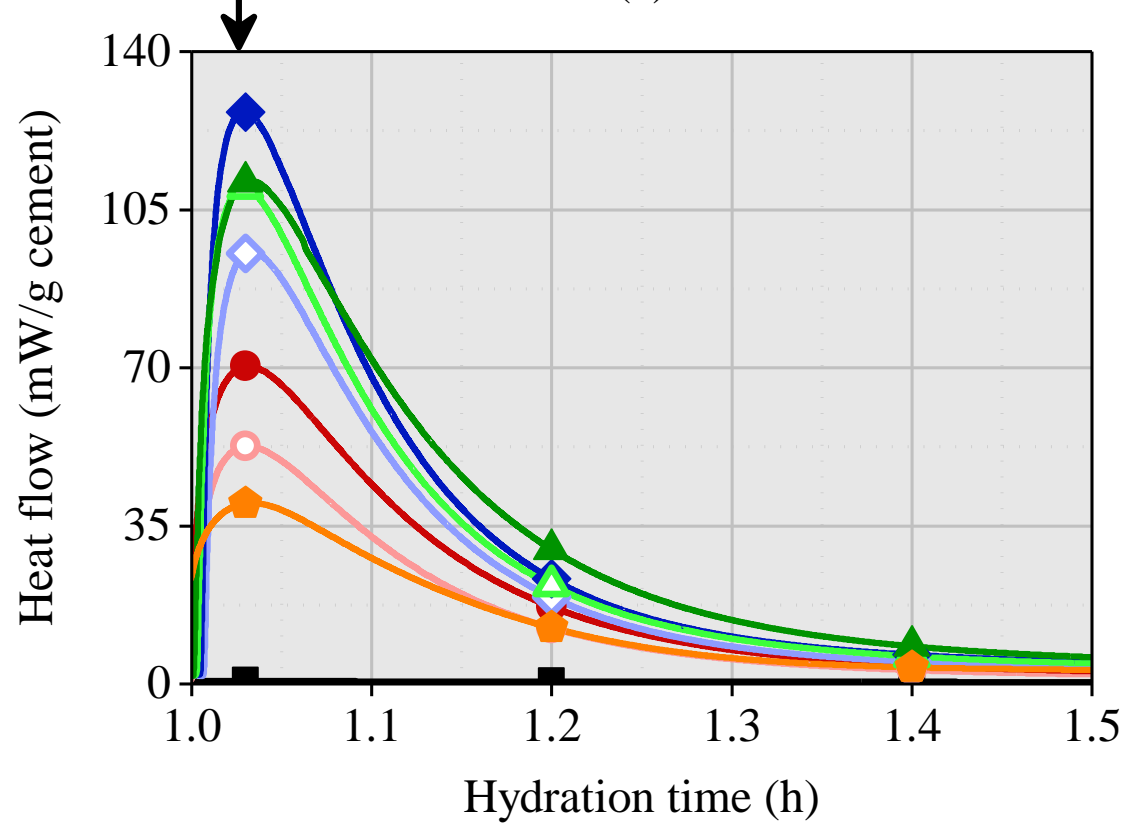

(b)

Figure A.3 - Heat flow curves of pastes OPC 94_G 6 from 0 to $24 \mathrm{~h}$ (a) and from 1.0 to $1.5 \mathrm{~h}$ (b) 


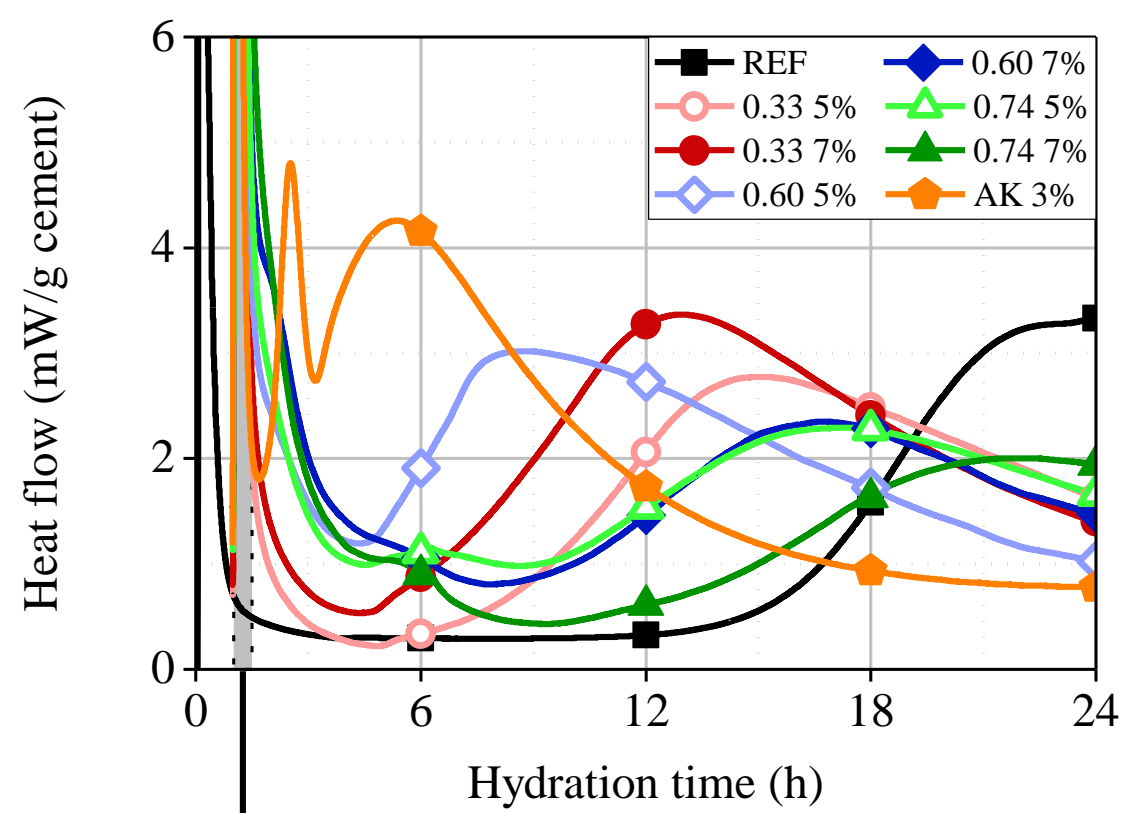

(a)

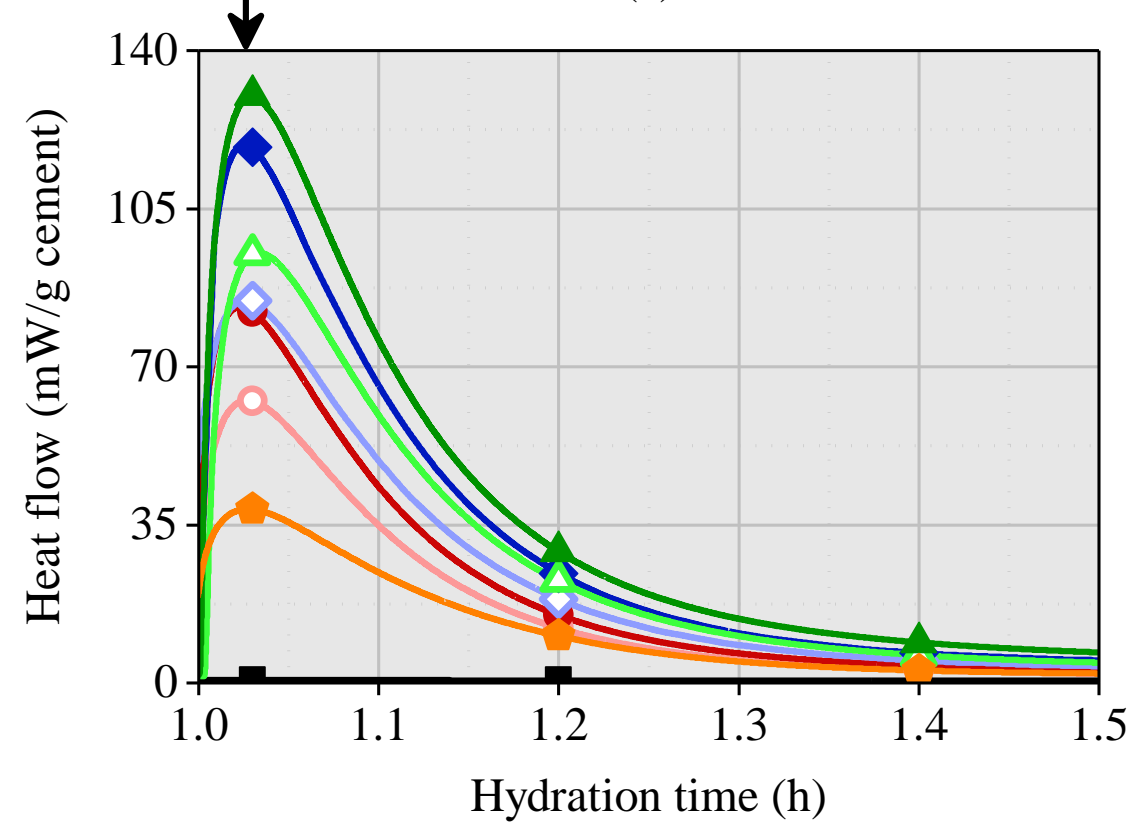

(b)

Figure A.4 - Heat flow curves of pastes OPC 96_H 3.38 from 0 to $24 \mathrm{~h}$ (a) and from 1.0 to $1.5 \mathrm{~h}$ (b). 


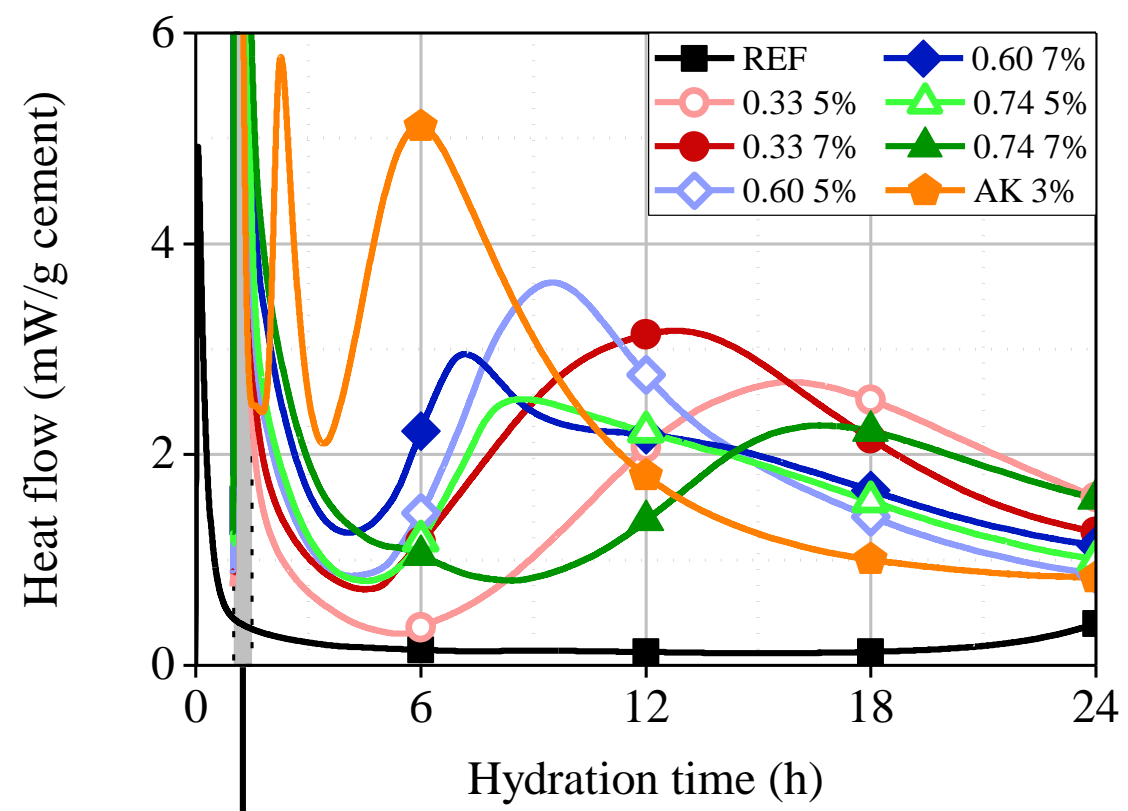

(a)

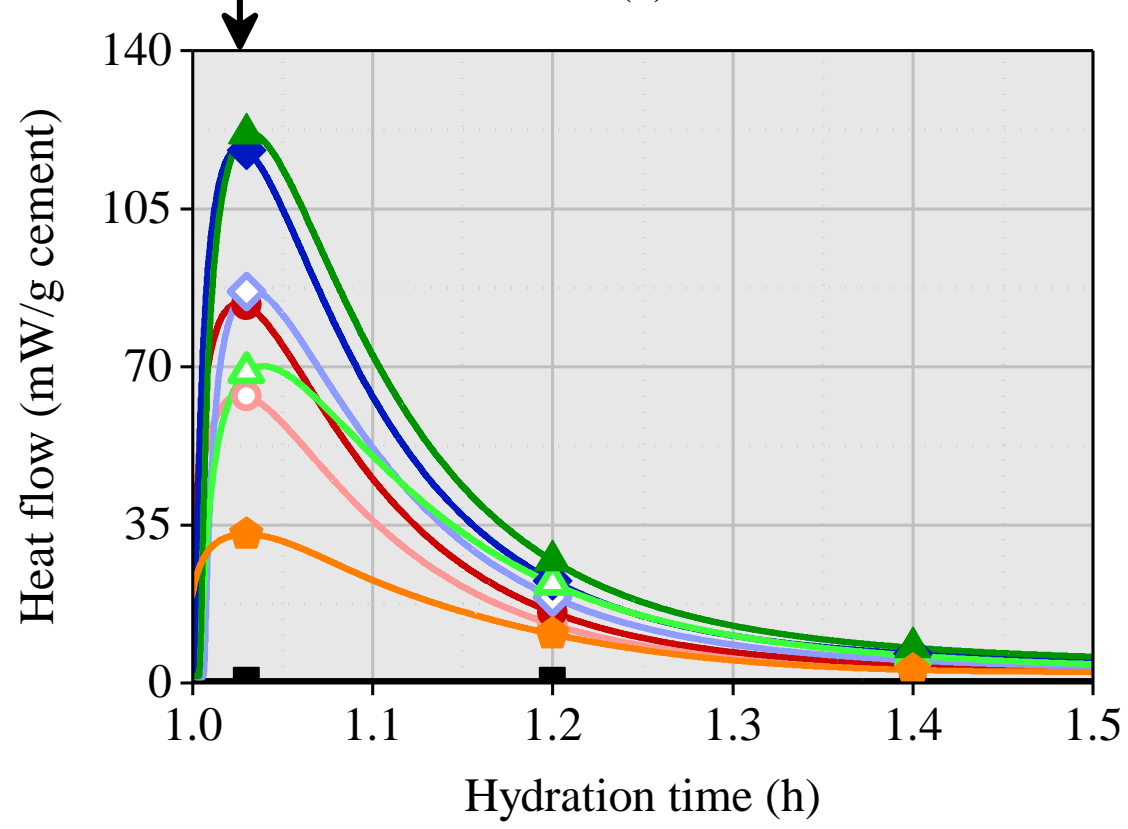

(b)

Figure A.5 - Heat flow curves of pastes OPC 96_G 4_F from 0 to $24 \mathrm{~h}$ (a) and from 1.0 to $1.5 \mathrm{~h}$ (b). 


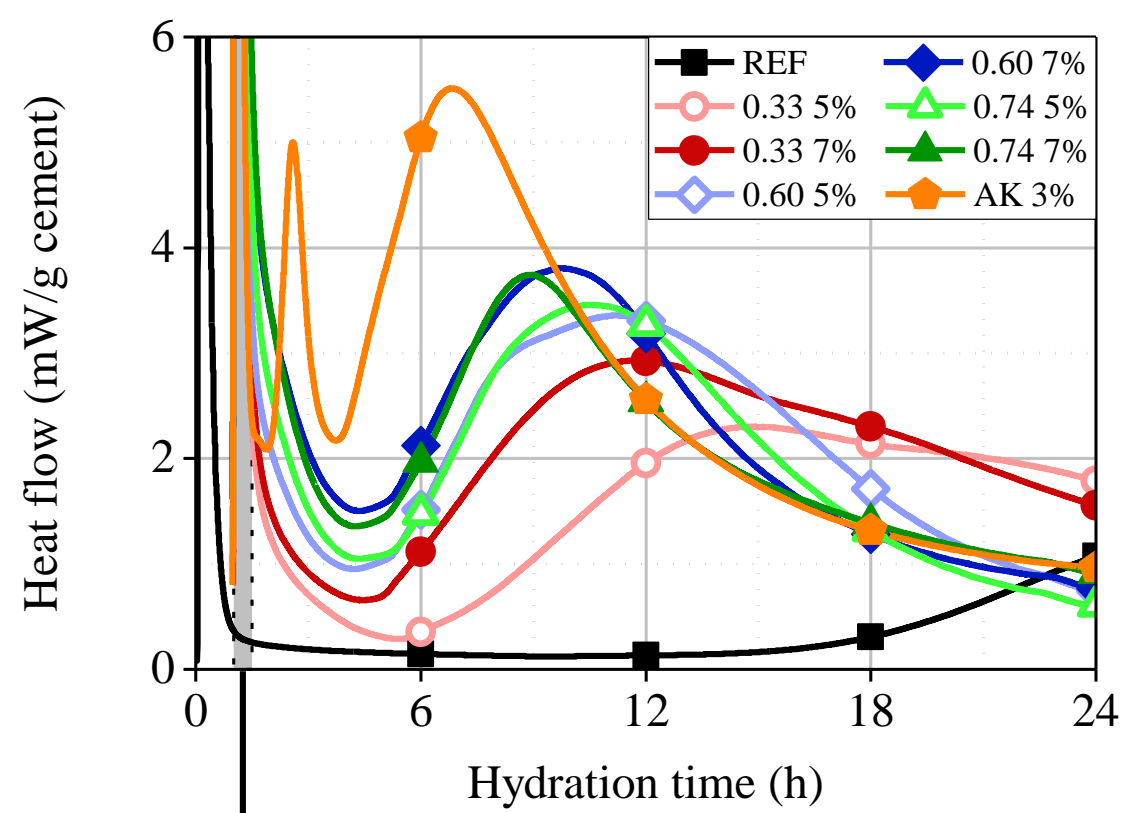

(a)

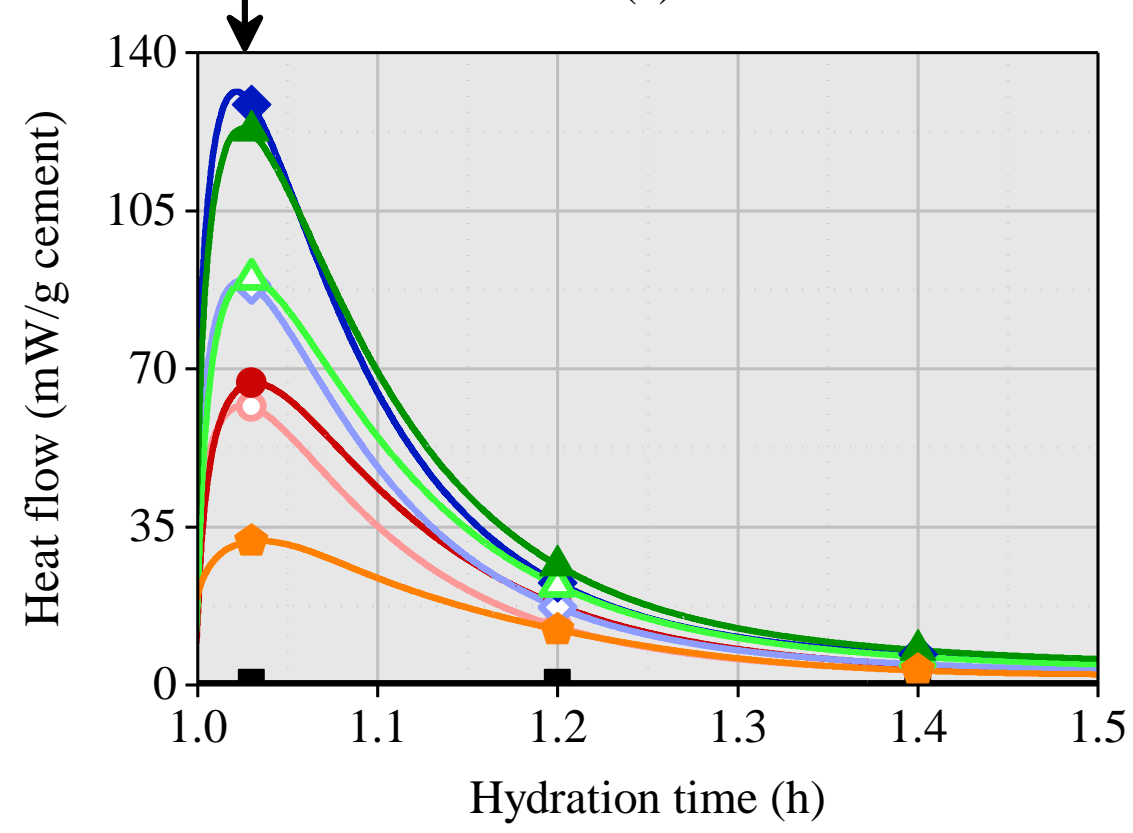

(b)

Figure A.6 - Heat flow curves of pastes OPC 94_G 6_F from 0 to $24 \mathrm{~h}$ (a) and from 1.0 to $1.5 \mathrm{~h}$ (b). 


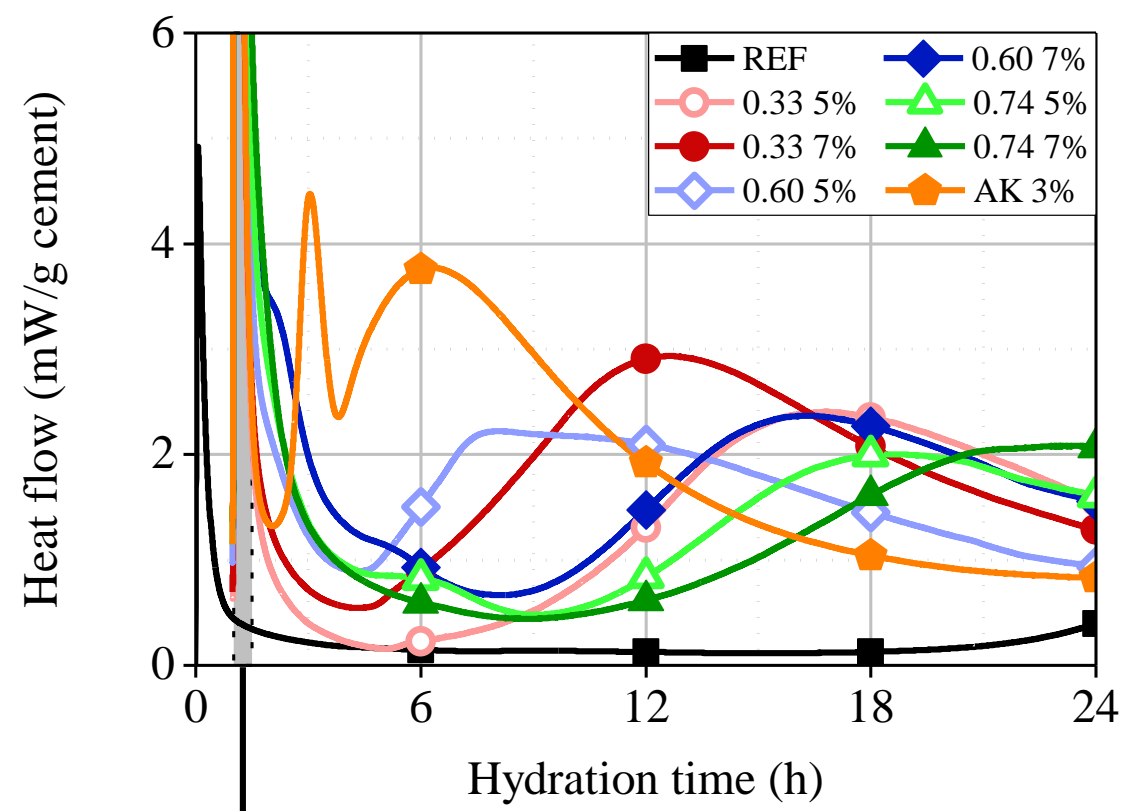

(a)

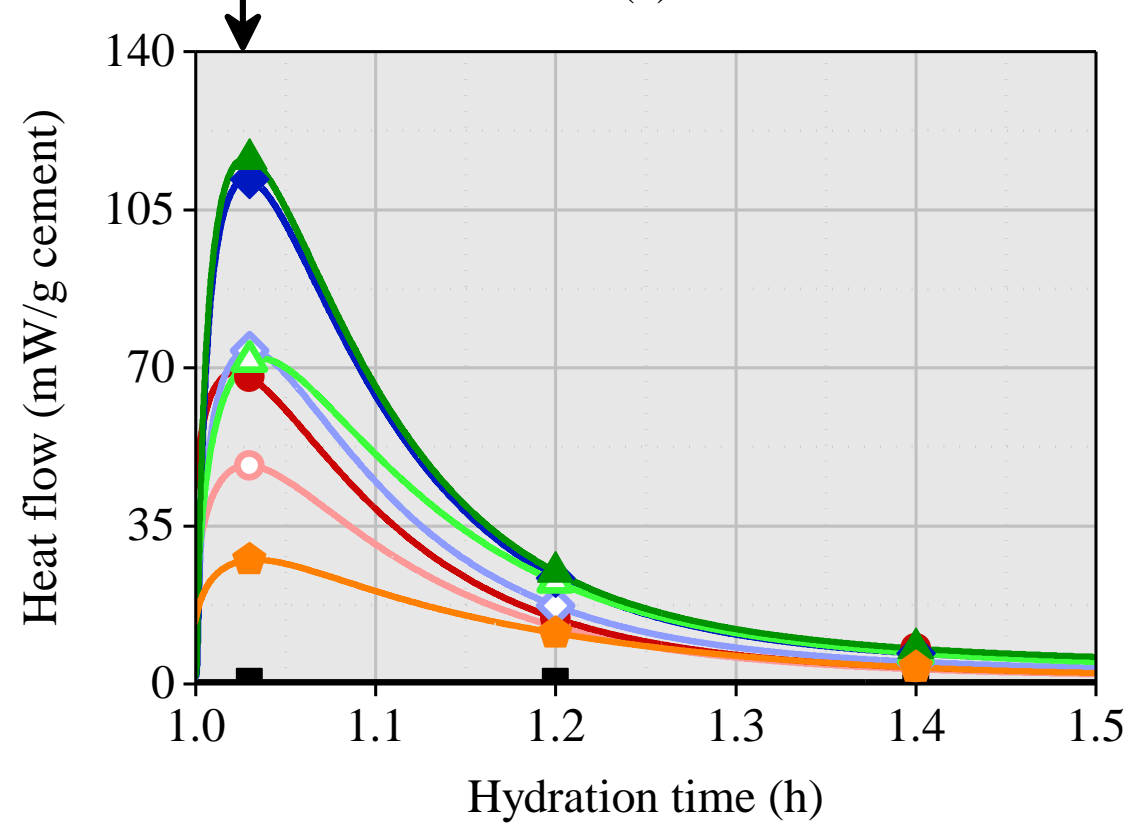

(b)

Figure A.7 - Heat flow curves of pastes OPC 96_H 3.38_F from 0 to $24 \mathrm{~h}$ (a) and from 1.0 to $1.5 \mathrm{~h}$ (b). 


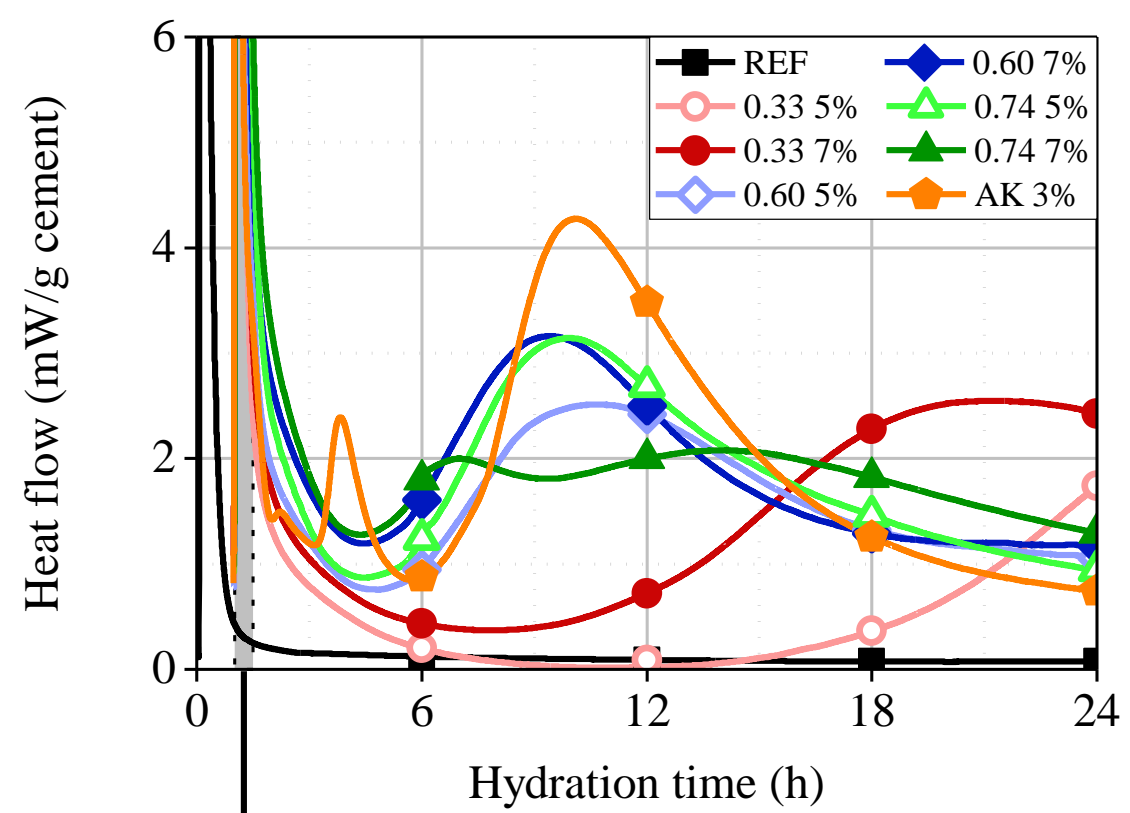

(a)

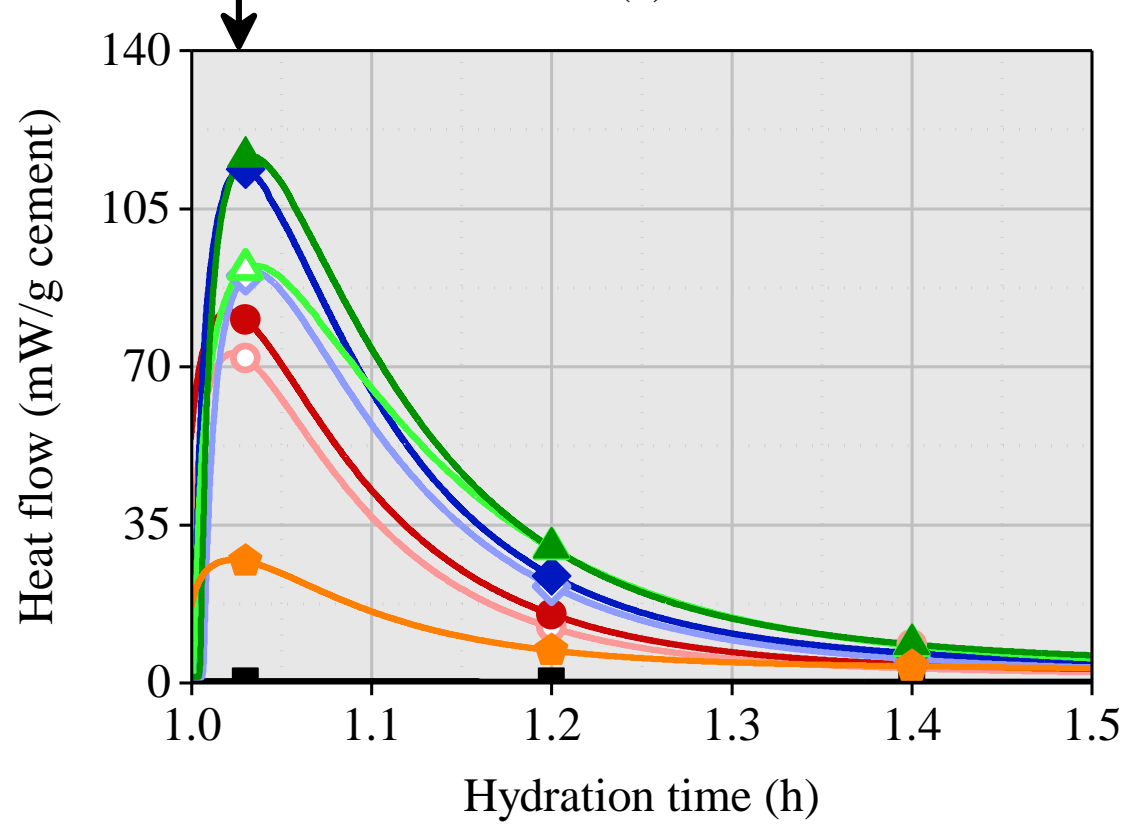

(b)

Figure A.8 - Heat flow curves of pastes SRC 96_G 4 from 0 to $24 \mathrm{~h}$ (a) and from 1.0 to $1.5 \mathrm{~h}$ (b). 
Table A.1 - Analysis of the heat flow curves obtained with the accelerated pastes.

\begin{tabular}{|c|c|c|c|c|c|c|c|}
\hline Paste & $\begin{array}{c}\text { Final } \\
\mathrm{C}_{3} \mathrm{~A} / \mathrm{SO}_{3} \\
\text { molar } \\
\text { ratio }^{\mathrm{a}}\end{array}$ & $\begin{array}{c}\text { Slope - } \\
\text { accelerator } \\
\text { peak } \\
(\mathbf{m W} / \mathbf{g . h})\end{array}$ & $\begin{array}{c}\text { Energy } \\
\text { released - } \\
\text { accelerator } \\
\text { peak }^{\mathbf{b}}(\mathrm{J} / \mathrm{g})\end{array}$ & $\begin{array}{l}\text { Induction } \\
\text { period (h) }\end{array}$ & $\begin{array}{c}\text { Slope } \\
\text { acceleration } \\
\text { - main peak } \\
\text { (mW/g.h) }\end{array}$ & $\begin{array}{c}\text { Energy } \\
\text { released - } \\
\text { main peak } \\
(\mathrm{J} / \mathrm{g})\end{array}$ & $\begin{array}{l}\text { Energy } \\
\text { released } \\
\text { until 24 } \\
\mathbf{h}^{\mathrm{d}}(\mathrm{J} / \mathrm{g})\end{array}$ \\
\hline $\begin{array}{l}\text { OPC 98_G 2 } \\
\text { AF 0.335\% }\end{array}$ & 0.85 & 1544 & 18.25 & 3.00 & 0.66 & 154.7 & 210.3 \\
\hline $\begin{array}{c}\text { OPC 98_G 2 } \\
\text { AF 0.337\% }\end{array}$ & 0.85 & 2072 & 27.10 & 2.45 & 0.84 & 156.7 & 217.0 \\
\hline $\begin{array}{c}\text { OPC 98_G 2- } \\
\text { AF } 0.605 \%\end{array}$ & 1.35 & 2437 & 28.57 & 8.74 & 0.42 & 152.0 & 187.2 \\
\hline $\begin{array}{c}\text { OPC } 98 \_ \text {G 2 } \\
\text { AF } 0.607 \%\end{array}$ & 1.77 & 2887 & 42.64 & 9.65 & 0.36 & 153.9 & 180.9 \\
\hline $\begin{array}{c}\text { OPC 98_G 2 } \\
\text { AF 0.74 5\% }\end{array}$ & 1.95 & 2131 & 34.67 & 13.54 & 0.30 & 161.3 & 123.6 \\
\hline $\begin{array}{c}\text { OPC 98_G 2- } \\
\text { AF 0.74 7\% }\end{array}$ & 4.03 & 1721 & 46.02 & 20.54 & 0.17 & 157.7 & 86.2 \\
\hline $\begin{array}{c}\text { OPC 98_G 2 } \\
\text { AK 3\% }\end{array}$ & 7.57 & 469 & 10.75 & 1.93 & 1.02 & 154.5 & 233.0 \\
\hline $\begin{array}{c}\text { OPC 96_G 4_- } \\
\text { AF 0.335\% }\end{array}$ & 0.56 & 1702 & 18.79 & 7.61 & 0.51 & 154.8 & 202.3 \\
\hline $\begin{array}{l}\text { OPC } 96-G 4 \\
\text { AF } 0.337 \%\end{array}$ & 0.56 & 2087 & 26.49 & 5.26 & 0.59 & 168.7 & 227.6 \\
\hline $\begin{array}{c}\text { OPC } 96 \_\mathrm{G} 4 \\
\mathrm{AF} 0.605 \%\end{array}$ & 0.75 & 2134 & 31.78 & 3.70 & 1.05 & 128.4 & 218.3 \\
\hline $\begin{array}{l}\text { OPC 96_G 4_- } \\
\text { AF 0.60 7\% }\end{array}$ & 0.87 & 3550 & 44.55 & 3.35 & 1.00 & 142.9 & 236.1 \\
\hline $\begin{array}{c}\text { OPC 96_G 4_- } \\
\text { AF 0.74 5\% }\end{array}$ & 0.91 & 2078 & 37.13 & 3.61 & 0.82 & 115.4 & 207.4 \\
\hline $\begin{array}{c}\text { OPC 96_G 4_- } \\
\text { AF } 0.747 \%\end{array}$ & 1.21 & 2302 & 50.93 & 9.24 & 0.25 & 124.7 & 197.2 \\
\hline $\begin{array}{c}\text { OPC 96_G 4_ } \\
\text { AK 3\% }\end{array}$ & 1.41 & 577 & 12.11 & 2.02 & 1.87 & 131.4 & 240.7 \\
\hline $\begin{array}{c}\text { OPC 94_G 6_ } \\
\text { AF } 0.335 \%\end{array}$ & 0.42 & 1294 & 16.14 & 7.86 & 0.46 & 166.3 & 196.5 \\
\hline $\begin{array}{c}\text { OPC } 94 \_ \text {G 6- } \\
\text { AF } 0.337 \%\end{array}$ & 0.42 & 1613 & 26.54 & 4.69 & 0.63 & 180.9 & 236.3 \\
\hline $\begin{array}{l}\text { OPC 94_G 6- } \\
\text { AF 0.60 5\% }\end{array}$ & 0.51 & 2766 & 34.28 & 3.85 & 0.77 & 136.9 & 236.8 \\
\hline $\begin{array}{c}\text { OPC 94_G 6_- } \\
\text { AF 0.60 7\% }\end{array}$ & 0.57 & 5112 & 47.28 & 3.49 & 0.82 & 144.4 & 256.5 \\
\hline $\begin{array}{c}\text { OPC 94_G 6- } \\
\text { AF 0.74 5\% }\end{array}$ & 0.59 & 3930 & 41.78 & 4.02 & 0.72 & 116.7 & 225.2 \\
\hline $\begin{array}{l}\text { OPC 94_G 6- } \\
\text { AF } 0.747 \%\end{array}$ & 0.70 & 3185 & 51.59 & 3.67 & 0.86 & 127.6 & 231.6 \\
\hline $\begin{array}{c}\text { OPC 94_G 6_ } \\
\text { AK 3\% }\end{array}$ & 0.76 & 717 & 13.56 & 1.98 & 1.40 & 160.3 & 255.5 \\
\hline $\begin{array}{c}\text { OPC 96_H 3.38_ } \\
\text { AF } 0.335 \%\end{array}$ & 0.56 & 1738 & 18.95 & 6.16 & 0.38 & 132.6 & 176.8 \\
\hline $\begin{array}{c}\text { OPC 96_H 3.38_ } \\
\text { AF } 0.337 \%\end{array}$ & 0.56 & 2603 & 27.73 & 4.17 & 0.42 & 154.7 & 209.5 \\
\hline $\begin{array}{c}\text { OPC 96_H 3.38_ } \\
\text { AF } 0.605 \%\end{array}$ & 0.75 & 2679 & 33.25 & 3.26 & 0.61 & 131.0 & 231.0 \\
\hline $\begin{array}{c}\text { OPC 96_H 3.38_ } \\
\text { AF } 0.607 \%\end{array}$ & 0.87 & 4498 & 47.40 & 7.97 & 0.26 & 120.6 & 204.4 \\
\hline $\begin{array}{c}\text { OPC 96_H 3.38_ } \\
\text { AF } 0.745 \%\end{array}$ & 0.91 & 2445 & 38.83 & 7.87 & 0.22 & 124.2 & 198.8 \\
\hline
\end{tabular}




\begin{tabular}{|c|c|c|c|c|c|c|c|}
\hline $\begin{array}{c}\text { OPC 96_H 3.38_ } \\
\text { AF } 0.747 \%\end{array}$ & 1.21 & 3819 & 56.75 & 10.64 & 0.19 & 129.7 & 168.4 \\
\hline $\begin{array}{c}\text { OPC 96_H 3.38_ } \\
\text { AK 3\% }\end{array}$ & 1.41 & 891 & 10.33 & 1.72 & 1.16 & 112.0 & 217.0 \\
\hline $\begin{array}{c}\text { OPC 96_G 4_ } \\
\text { F_AF } 0.335 \%\end{array}$ & 0.56 & 1693 & 20.27 & 5.22 & 0.32 & 133.1 & 181.8 \\
\hline $\begin{array}{l}\text { OPC 96_G 4 } \\
\text { F_AF } 0.337 \%\end{array}$ & 0.56 & 2511 & 28.75 & 3.44 & 0.44 & 148.3 & 211.7 \\
\hline $\begin{array}{l}\text { OPC 96_G 4_ } \\
\text { F_AF } 0.605 \%\end{array}$ & 0.79 & 2551 & 31.76 & 3.85 & 0.79 & 113.6 & 199.4 \\
\hline $\begin{array}{l}\text { OPC 96_G 4_ } \\
\text { F_AF } 0.607 \%\end{array}$ & 0.95 & 3660 & 45.62 & 3.38 & 0.82 & 121.7 & 210.2 \\
\hline $\begin{array}{l}\text { OPC 96_G 4 } \\
\text { F_AF } 0.745 \%\end{array}$ & 1.00 & 1522 & 30.90 & 3.93 & 0.63 & 102.7 & 190.0 \\
\hline $\begin{array}{l}\text { OPC 96_G 4 } \\
\text { F_AF } 0.747 \%\end{array}$ & 1.46 & 3428 & 51.05 & 8.28 & 0.26 & 107.9 & 194.6 \\
\hline $\begin{array}{l}\text { OPC 96_G 4_ } \\
\text { F_AK 3\% }\end{array}$ & 1.82 & 655 & 9.18 & 2.10 & 1.64 & 119.0 & 227.6 \\
\hline $\begin{array}{l}\text { OPC 94_G 6_ } \\
\text { F_AF } 0.335 \%\end{array}$ & 0.42 & 1532 & 20.03 & 4.82 & 0.29 & 136.6 & 170.4 \\
\hline $\begin{array}{l}\text { OPC 94_G 6_ } \\
\text { F_AF } 0.337 \%\end{array}$ & 0.42 & 1484 & 26.25 & 3.41 & 0.45 & 164.4 & 209.8 \\
\hline $\begin{array}{l}\text { OPC 94_G 6_ } \\
\text { F_AF 0.60 5\% }\end{array}$ & 0.53 & 2523 & 32.45 & 3.61 & 0.66 & 131.4 & 220.4 \\
\hline $\begin{array}{l}\text { OPC 94_G 6_ } \\
\text { F_AF } 0.607 \%\end{array}$ & 0.60 & 4275 & 50.14 & 3.56 & 0.67 & 121.6 & 242.8 \\
\hline $\begin{array}{c}\text { OPC 94_G 6_ } \\
\text { F_AF 0.74 5\% }\end{array}$ & 0.62 & 2324 & 37.77 & 3.76 & 0.66 & 115.0 & 213.4 \\
\hline $\begin{array}{l}\text { OPC 94_G 6_ } \\
\text { F_AF } 0.747 \%\end{array}$ & 0.78 & 3979 & 52.42 & 3.61 & 0.73 & 116.5 & 227.9 \\
\hline $\begin{array}{c}\text { OPC 94_G 6_ } \\
\text { F_AK 3\% }\end{array}$ & 0.87 & 544 & 10.21 & 2.28 & 1.37 & 158.8 & 257.6 \\
\hline $\begin{array}{c}\text { OPC 96_H 3.38_ } \\
\text { F_AF } 0.335 \%\end{array}$ & 0.56 & 1118 & 15.67 & 6.88 & 0.30 & 108.1 & 152.6 \\
\hline $\begin{array}{c}\text { OPC 96_H 3.38_ } \\
\text { F_AF } 0.337 \%\end{array}$ & 0.56 & 1897 & 23.97 & 3.41 & 0.37 & 136.9 & 192.2 \\
\hline $\begin{array}{c}\text { OPC 96_H 3.38_- } \\
\text { F_AF } 0.605 \%\end{array}$ & 0.79 & 1913 & 27.63 & 3.18 & 0.49 & 97.1 & 180.4 \\
\hline $\begin{array}{c}\text { OPC 96_H 3.38_ } \\
\text { F_AF } 0.607 \%\end{array}$ & 0.95 & 3049 & 45.22 & 7.87 & 0.31 & 110.5 & 191.7 \\
\hline $\begin{array}{c}\text { OPC 96_H 3.38_ } \\
\text { F_AF } 0.745 \%\end{array}$ & 1.00 & 1458 & 33.51 & 9.09 & 0.24 & 92.9 & 158.7 \\
\hline $\begin{array}{c}\text { OPC 96_H 3.38_- } \\
\text { F_AF } 0.747 \%\end{array}$ & 1.46 & 3303 & 48.25 & 9.87 & 0.17 & 98.7 & 156.5 \\
\hline $\begin{array}{c}\text { OPC 96_H 3.38_ } \\
\text { F_AK 3\% }\end{array}$ & 1.82 & 512 & 8.08 & 2.35 & 1.03 & 107.5 & 206.4 \\
\hline $\begin{array}{c}\text { SRC 96_G 4_- } \\
\text { AF } 0.335 \%\end{array}$ & 0.17 & 2264 & 21.83 & 16.17 & 0.24 & 131.1 & 83.0 \\
\hline $\begin{array}{c}\text { SRC 96_G 4_ } \\
\text { AF } 0.337 \% \\
\end{array}$ & 0.17 & 2339 & 28.61 & 9.78 & 0.27 & 145.0 & 159.0 \\
\hline $\begin{array}{c}\text { SRC 96_G 4_ } \\
\text { AF } 0.605 \%\end{array}$ & 0.24 & 2460 & 35.39 & 3.85 & 0.49 & 86.8 & 181.5 \\
\hline $\begin{array}{l}\text { SRC 96_G 4_ } \\
\text { AF } 0.607 \%\end{array}$ & 0.28 & 3858 & 45.58 & 3.85 & 0.61 & 99.1 & 207.0 \\
\hline $\begin{array}{c}\text { SRC 96_G 4_ } \\
\text { AF } 0.745 \%\end{array}$ & 0.30 & 1954 & 46.0 & 3.99 & 0.65 & 107.1 & 201.8 \\
\hline $\begin{array}{c}\text { SRC 96_G 4_ } \\
\text { AF } 0.747 \%\end{array}$ & 0.41 & 3736 & 52.40 & 3.44 & 0.43 & 123.0 & 204.9 \\
\hline
\end{tabular}




\begin{tabular}{cccccccc}
\hline $\begin{array}{c}\text { SRC 96_G 4_ } \\
\text { AK 3\% }\end{array}$ & 0.49 & 716 & 4.66 & 5.59 & 1.31 & 104.5 & 197.8 \\
\hline
\end{tabular}

${ }^{\mathrm{a}}$ The final $\mathrm{C}_{3} \mathrm{~A} / \mathrm{SO}_{3}$ ratio was calculated considering the sulfate amount remaining after accelerator reaction and the initial $\mathrm{C}_{3} \mathrm{~A}$ content of cements.

${ }^{b}$ The energy corresponding to the accelerator peak was corrected using the variation of heat generated by the removal of the sample from the calorimeter for the addition of the accelerator. The area under the curve was calculated from 1.0 to $1.5 \mathrm{~h}$.

${ }^{c}$ The area under the main hydration peak was calculated from the end of the induction period until the time when the heat flow reached $1.0 \mathrm{~mW} / \mathrm{g}$ of cement in the deceleration period.

${ }^{\mathrm{d}}$ Calculated by the total energy released until $24 \mathrm{~h}$ minus the energy released in the accelerator peak, in order to evaluate the energy associated with cement hydration.

\section{References}

[1] I. Galobardes, Characterization and control of wet-mix sprayed concrete with accelerators. Ph.D. Thesis (2013).

[2] L.R. Prudencio, Accelerating admixtures for shotcrete. Cem. Concr. Comp. 20 (1998) 213-219.

[3] A.D. de Figueiredo, Early strength and physical properties in accelerated shotcrete in Shotcrete for Underground Support VIII, Campos do Jordão (Brazil), 11-15 April, 1999.

[4] A. Ansell, Structural behavior of shotcrete on irregular rock surfaces, in: Shotcrete: Elements of a system, CRC Press, 2010: pp. 11-19.

[5] R.P. Salvador, S.H.P. Cavalaro, M. Cano, A.D. Figueiredo, Influence of spraying on the early hydration of accelerated cement pastes, Cem. Concr. Res. 88 (2016) 7-19. doi:10.1016/j.cemconres.2016.06.005.

[6] I. Galobardes, S.H. Cavalaro, A. Aguado, T. Garcia, Estimation of the modulus of elasticity for sprayed concrete, Constr. Build. Mater. 53 (2014) 48-58. doi:10.1016/j.conbuildmat.2013.11.046.

[7] R.P. Salvador, S.H.P. Cavalaro, A. Rueda, A.D. Figueiredo, Effect of cement composition on the reactivity of alkali-free accelerating admixtures for shotcrete. In: $7^{\text {th }}$ International Symposium on Sprayed Concrete. Sandefjord, Norway, June/2014: pp. 350360. 
[8] C. Maltese, C. Pistolesi, A. Bravo, F. Cella, T. Cerulli, D. Salvioni, Effects of setting regulators on the efficiency of an inorganic acid based alkali-free accelerator reacting with a Portland cement, Cem. Concr. Res. 37 (2007) 528-536. doi:10.1016/j.cemconres.2007.01.002.

[9] C. Maltese, C. Pistolesi, A. Bravo, F. Cella, T. Cerulli, D. Salvioni, A case history: Effect of moisture on the setting behaviour of a Portland cement reacting with an alkalifree accelerator, 37 (2007) 856-865. doi:10.1016/j.cemconres.2007.02.020.

[10] D. Lootens, B. Lindlar, R.J. Flatt, Some peculiar aspects of shotcrete accelerators, in: First international conference on microstructure related to durability of cementitious composites, Nanjing (China), 13-15 october, 2008: pp. 1255-1261.

[11] P. Juilland, Early hydration of cementitious systems. Ph.D. Thesis (2009).

[12] R.P. Salvador, S.H.P. Cavalaro, I. Segura, A.D. Figueiredo, J. Pérez, Early age hydration of cement pastes with alkaline and alkali-free accelerators for sprayed concrete, Constr. Build. Mater. 111 (2016) 386-398. doi:10.1016/j.conbuildmat.2016.02.101.

[13] Q. Xu, J. Stark, Early hydration of ordinary Portland cement with an alkaline accelerator, Advances in Cement Research, 17 (2005) 1-8.

[14] R.P. Salvador, S.H.P. Cavalaro, R. Monte, A.D. Figueiredo, Characterization of chemical and mechanical properties of accelerated sprayed cement matrices, research in progress.

[15] A. Quennoz, K.L. Scrivener, Interactions between alite and $C_{3} A$-gypsum hydrations in model cements, Cem. Conc. Res. 44 (2013) 46-54. doi:10.1016/j.cemconres.2012.10.018.

[16] D.P. Bentz, E.J. Garboczi, C.J. Haecker, O.M. Jensen, Effects of cement particle size distribution on performance properties of Portland cement-based materials, Cem. Concr. Res. 29 (1999) 1663-1671. doi:10.1016/S0008-8846(99)00163-5.

[17] H.F.W. Taylor, Cement Chemistry. $2^{\text {nd }}$ ed. Thomas Telford Publishing, 1997.

[18] J.A. Dean, Lange's handbook of chemistry. 15th ed. McGrawl-Hill Inc, 1999.

[19] AENOR. UNE-EN 197-1:2011. Cement - Part 1: Composition, specifications and conformity criteria for common cements, 2011. 
[20] A. Quennoz, E. Galucci, K.L. Scrivener, Calcium silicate - calcium aluminate interactions and their influence on cement early hydration. In: $13^{\text {th }}$ International Congress on the Chemistry of Cement. Madrid, Spain, July/2011: pp. 218.

[21] E.M. Gartner, J.F. Young, D.A. Damidot, I. Jawed, Hydration of Portland cement, in: P. Barnes, J. Bensted (Eds.), Struct. Perform. Cem., 2nd ed., Spon Press, London, 2002: pp. 57-113.

[22] I.C. Madsen, N.V.Y. Scarlett, A. Kern, Description and survey of methodologies for the determination of amorphous content via X-ray powder diffraction, Zeitschrift Für Krist. 226 (12) (2011) 944-955. doi:10.1524/zkri.2011.1437.

[23] M. Arndt, K. Lipus, A. Becker, Method performance study on heat of hydration determination of cement by heat conduction calorimetry. In: First International Proficiency Testing Conference. Sinaia, Romania, October/2007: pp. 268-275.

[24] S. Pourchet, L. Regnaud, J.P. Perez, A. Nonat, Early $\mathrm{C}_{3}$ A hydration in the presence of different kinds of calcium sulfate, Cem. Concr. Res. 39 (2009) 989-996. doi:10.1016/j.cemconres.2009.07.019.

[25] S. Garrault, A. Nonat, Y. Sallier, L. Nicolaeau, On the origin of the dormant period of cement hydration. In: $13^{\text {th }}$ International Congress on the Chemistry of Cement. Madrid, Spain, July/2011: pp. 240.

[26] T. Chappex, K.L. Scrivener, The effect of aluminum in solution on the dissolution of amorphous silica and its relation to cementitious systems, J. Am. Ceram. Soc. 96 (2013) 592-597. doi:10.1111/jace.12098.

[27] T.P. DiNoia, P.J. Sandberg, Alkali-free shotcrete accelerator interactions with cement and admixtures in Shotcrete: Engineering Developments, 2004, 137-144.

[28] H. Minard, S. Garrault, L. Regnaud, A. Nonat, Mechanisms and parameters controlling the tricalcium aluminate reactivity in the presence of gypsum, Cem. Concr. Res. 37 (2007) 1418-1426. doi:10.1016/j.cemconres.2007.06.001.

[29] M. Zajac, A. Rossberg, G. Le Saout, B. Lothenbach, Influence of limestone and anhydrite on the hydration of Portland cements, Cem. Concr. Compos. 46 (2014) 99-108. doi:10.1016/j.cemconcomp.2013.11.007.

[30] J. Bizzozero, K.L. Scrivener, Limestone reaction in calcium aluminate cementcalcium sulfate systems, Cem. Concr. Res. 76 (2015) 159-169. doi:10.1016/j.cemconres.2015.05.019. 
[31] B. Lothenbach, G.L. Saout, E. Gallucci, K.L. Scrivener, Influence of limestone on the hydration of Portland cements, Cem. Concr. Res. 38 (2008) 848-860. doi:10.1016/j.cemconres.2008.01.002.

[32] T. Matschei, B. Lothenbach, F.P. Glasser, The AFm phase in Portland cement, Cem. Concr. Res. 37 (2007) 118-130. doi:10.1016/j.cemconres.2006.10.010.

[33] E. Berodier, K. Scrivener, Understanding the filler effect on the nucleation and growth of C-S-H, J. Am. Ceram. Soc. 12 (2014) 3764-3773. doi:10.1111/jace.13177. 